Research Article

\title{
Pseudodynamic Bearing Capacity Analysis of Shallow Strip Footing Using the Advanced Optimization Technique "Hybrid Symbiosis Organisms Search Algorithm" with Numerical Validation
}

\author{
Arijit Saha (D), ${ }^{1}$ Apu Kumar Saha, ${ }^{2}$ and Sima Ghosh ${ }^{1}$ \\ ${ }^{1}$ Department of Civil Engineering, National Institute of Technology Agartala, Barjala, Jirania, 799046 West Tripura, India \\ ${ }^{2}$ Department of Mathematics, National Institute of Technology Agartala, Barjala, Jirania, 799046 West Tripura, India \\ Correspondence should be addressed to Arijit Saha; sahaarijit20@gmail.com
}

Received 26 July 2017; Revised 25 September 2017; Accepted 9 October 2017; Published 5 April 2018

Academic Editor: Moacir Kripka

Copyright (c) 2018 Arijit Saha et al. This is an open access article distributed under the Creative Commons Attribution License, which permits unrestricted use, distribution, and reproduction in any medium, provided the original work is properly cited.

\begin{abstract}
The analysis of shallow foundations subjected to seismic loading has been an important area of research for civil engineers. This paper presents an upper-bound solution for bearing capacity of shallow strip footing considering composite failure mechanisms by the pseudodynamic approach. A recently developed hybrid symbiosis organisms search (HSOS) algorithm has been used to solve this problem. In the HSOS method, the exploration capability of SQI and the exploitation potential of SOS have been combined to increase the robustness of the algorithm. This combination can improve the searching capability of the algorithm for attaining the global optimum. Numerical analysis is also done using dynamic modules of PLAXIS-8.6v for the validation of this analytical solution. The results obtained from the present analysis using HSOS are thoroughly compared with the existing available literature and also with the other optimization techniques. The significance of the present methodology to analyze the bearing capacity is discussed, and the acceptability of HSOS technique is justified to solve such type of engineering problems.
\end{abstract}

\section{Introduction}

The subject of bearing capacity is one of the important aspects of geotechnical engineering problems. Loads from buildings are transmitted to the foundation by columns or by load-bearing walls of the structures. Many researchers like Prandtl [1], Terzaghi [2], Meyerhof [3, 4], Vesic [5, 6], and many more have investigated the mechanisms of bearing capacity of foundation under a static loading condition. Due to seismic loading, foundations may experience a reduction in bearing capacity and an increase in settlement. Two sources of loading must be taken into consideration, initial loading due to lateral forces imposed on superstructure and kinematic loading due to ground movements developed during the earthquake. The pioneering works in determining the seismic bearing capacity of shallow strip footings were done by Budhu and Al-Karni [7],
Dormieux and Pecker [8], Soubra [9-11], Richards et al. [12], Choudhury and Subha Rao [13], Kumar and Ghosh [14], and many others using pseudostatic approach with the help of different solution techniques such as method of slices, limit equilibrium, method of stress characteristics, and upper bound limit analysis. Apart from these analytical researchers, Shafiee and Jahanandish [15] and Chakraborty and Kumar [16] used finite element method to estimate the seismic bearing capacity of strip footings on the soil using PLAXIS-2D considering the pseudostatic approach. Since, in the pseudostatic method, the dynamic loading induced by the earthquake is considered as time-independent, which ultimately assumes that the magnitude and phase of acceleration are uniform through the soil layer, pseudodynamic analysis is developed where the effects of both shear and primary waves are considered along with the period of lateral shaking. Ghosh [17] and Saha and Ghosh [18] 
evaluated pseudodynamic bearing capacity using limit analysis method and limit equilibrium method, respectively, considering the linear failure surface. In the earlier analyses, the resistance of unit weight, surcharge, and cohesion is considered separately. Therefore, if the solution was done for shallow strip footing resting on $c-\Phi$ soil, there will be three separate coefficients: one for unit weight, another for surcharge, and the other for cohesion. But in a practical situation, there will be a single failure mechanism for the simultaneous resistance of unit weight, surcharge, and cohesion. Thus, an attempt is made to present a single seismic bearing capacity coefficient for the simultaneous resistance of unit weight, surcharge, and cohesion. Here, in this paper, the pseudodynamic bearing capacity of shallow strip footing considering composite failure mechanism resting on $c-\Phi$ soil is solved using the upper-bound limit analysis method. A relative ease in solving geometrically complex multidimensional problem renders limit analysis, attractive as an alternative to numerical codes. The kinematic method of limit analysis hinges on constructing a velocity field that is admissible for a rigid-perfect plastic material obeying the associative flow rule.

Nowadays, nature-based global optimization algorithms such as genetic algorithms (GA), particle swarm optimization (PSO) algorithm, and many other algorithms have been successfully applied to solve different science and engineering complex optimization problems, especially civil engineering problems such as slope stability $[19,20,21-28]$, retaining walls [29-31], and structural design [32]. Cheng and Prayogo [33] introduced a new nature-based optimization technique, called symbiotic organisms search (SOS) algorithm. This technique is based on the interactive relationship among the organism in the ecosystem. It has no algorithm-specific control parameters. The SOS algorithm has been successfully applied to solve different engineering optimization problems [34-38]. Recently, Nama et al. [39] proposed a hybrid algorithm called hybrid symbiotic organisms search (HSOS) algorithm, which is the combination of SOS algorithm and simple quadratic interpolation method [40]. Here, in this paper, HSOS algorithm is used to optimise the pseudodynamic bearing capacity of shallow strip footing considering upper bound limit analysis method. Mathematically, the problem can be represented as a nonlinear hard optimization problem, which can be solved by the HSOS algorithm which is found to be a more satisfactory optimum solution and can be used for designing the shallow strip footing. In the HSOS algorithm, failure surface angle $(\alpha, \beta)$ and $t / T$ are considered as the search variables. So, it can be applied to obtain optimal solutions in the different fields of science and engineering. Numerical analysis is also done using dynamic module of PLAXIS-8.6v software to validate this analytical solution. Results are presented in tabular form including comparison with other available analyses. Effects of a wide range of variation of parameters like soil friction angle $(\Phi)$, cohesion factor $\left(2 c / \gamma B_{0}\right)$, depth factor $\left(D_{f} / B_{0}\right)$, and horizontal and vertical seismic accelerations $\left(k_{h}, k_{v}\right)$ on the normalized reduction factor $\left(N_{\gamma \mathrm{e}} / N_{\gamma_{\mathrm{s}}}\right)$ have been studied.
Therefore, the main contributions of this paper are summarized as follows:

(i) Evaluation of pseudodynamic bearing capacity coefficient of shallow strip footing resting on $c$ - $\Phi$ soil considering composite failure surface using upper bound limit analysis method.

(ii) A single pseudodynamic bearing capacity coefficient is presented here considering the simultaneous resistance of unit weight, surcharge, and cohesion.

(iii) A recent hybrid optimization algorithm (called HSOS) is used to solve the pseudodynamic bearing capacity minimization optimization problem.

(iv) PLAXIS-8.6v software is used to solve this abovementioned problem numerically for the validation of the analytical formulation.

(v) The obtained results are compared with the other results which are available in literature and the results obtained by other state-of-the-art algorithms.

The remaining part of the paper is organized as follows: Section 2 discusses the formulation of the real-world geotechnical earthquake engineering optimization problem such as the pseudodynamic bearing capacity of a shallow foundation. The overview of the optimization algorithm HSOS is presented in Section 3. Section 4 presents discussions of the results obtained by the HSOS algorithm to show the efficiency and accuracy of this hybrid algorithm for solving this engineering optimization problem. Numerical analysis of shallow strip footing using the dynamic module of PLAXIS-8.6v software and the validation of analytical formulation are discussed in Section 5, and finally, Section 6 presents the conclusion and the summary of the outcome of the paper.

\section{Formulation of Pseudodynamic Bearing Capacity Coefficient}

2.1. Consideration of Model. Let us consider a shallow strip footing of width $\left(B_{0}\right)$ resting below the ground surface at a depth of $D_{f}$ over which a load $(P)$ of column acts. The homogeneous soil of effective unit weight $\gamma$ has MohrCoulomb characteristic $c-\Phi$ and can be considered as a rigid plastic body. For shallow foundation $\left(D_{f} \leq B_{0}\right)$, the overburden pressure is idealized as a surcharge $\left(q=\gamma D_{f}\right)$ which acts over the length of BC. The classical twodimensional slip line field obtained by Prandtl [1] is the traditional failure mechanism which has three regions such as active zone, passive zone, and logarithmic radialfan transition zone. In this composite failure mechanism, half of the failure is assumed to occur along the surface AEDC, which is composed of a triangular elastic zone $\mathrm{ABE}$, triangular passive Rankine zone $\mathrm{BDC}$, and in between them a log spiral radial shear zone BDE shown in Figure 1(a) [41]. It is a composite mechanism that is defined by the angular parameters $\alpha$ and $\beta$ in which the logspiral slip surface ED is a tangent to lines $\mathrm{AE}$ and $\mathrm{DC}$ at $\mathrm{E}$ and D, respectively. Figures 2 and 3 show the detailed free 


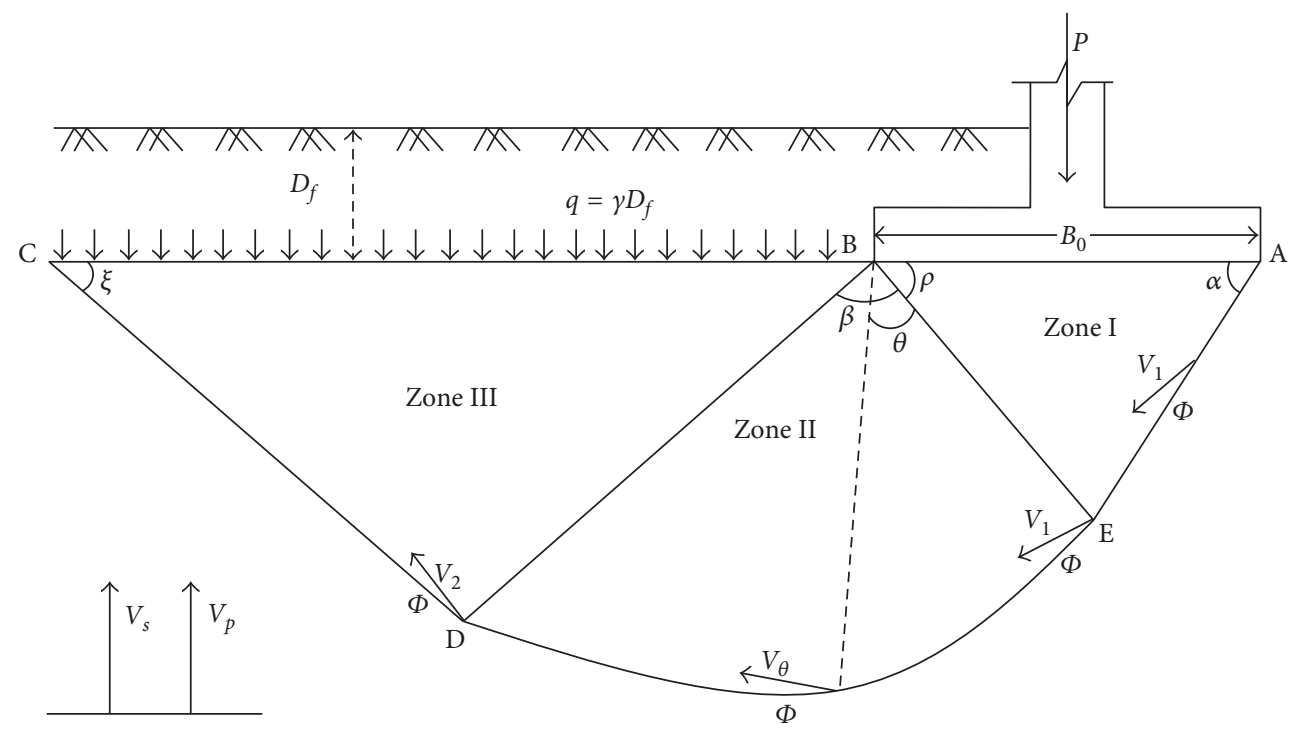

(a)

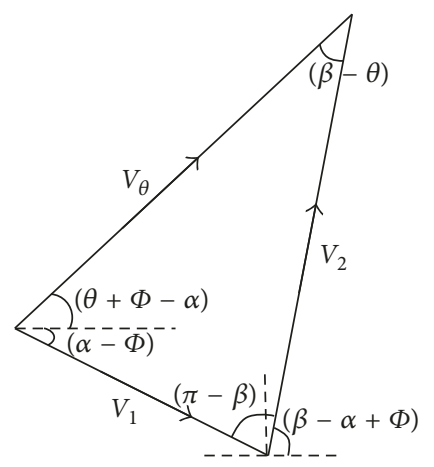

(b)

FIgURE 1: Composite failure mechanism [41]. (a) Collapse mechanism. (b) Velocity hodograph.

body diagram of the elastic zone $\mathrm{ABE}$ and composite passive Rankine zone and the log-spiral shear zone BEDC, respectively.

2.2. Collapse Mechanism. At collapse, it is assumed that the footing and the underlying zone ABE moves in phase with each other at the same absolute velocity $V_{1}$ making an angle $\Phi$ with the discontinuity line AE in order to represent the normality condition for an associated flow rule Coulomb material. Hence, there is no dissipation of energy along the soil-structure interface. Whereas the radial log-spiral shearing zone BED is bounded by a log-spiral curve ED. The equation for the curve in polar coordinates $(r, \theta)$ is $r=r_{0} e^{\theta \tan \phi}$. The centre of this log-spiral ED is at point $\mathrm{B}$, and the radius $r_{0}$ is the length of the line $\mathrm{BE}$, where $r_{0}=B_{0} \sin \alpha / \cos \phi$ and the width of the footing $\mathrm{AB}=B_{0}$. Note that, in this mechanism, we have assumed that the line $\mathrm{AE}$ is a tangent to the log-spiral curve at point $\mathrm{E}$; hence, there is no velocity discontinuity along $\mathrm{BE}$. The radial shear zone BED may be considered to be composed of a sequence of rigid triangles, as in the investigations by Chen, using the symmetrical Hill and Prandtl's

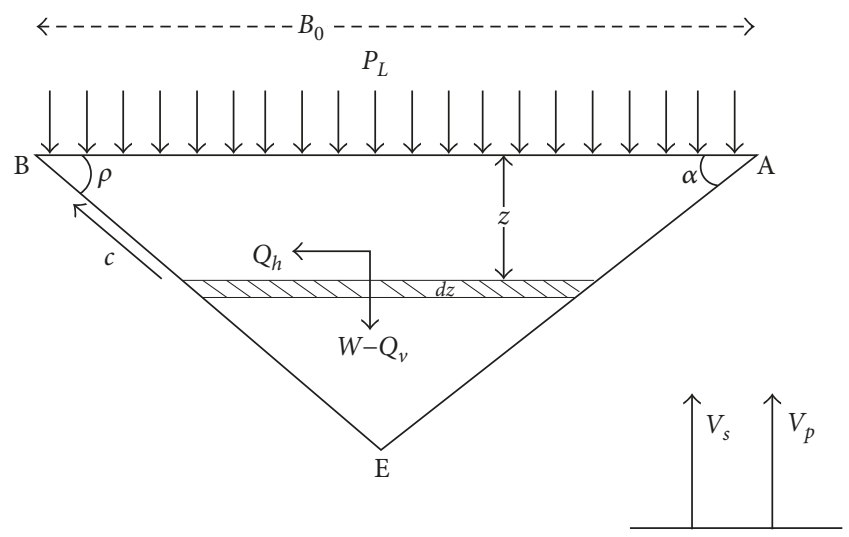

FIgURE 2: Elastic wedge.

mechanisms. All the small triangles move as rigid bodies in directions which make an angle $\Phi$ with the discontinuity line ED. The velocity of each small triangle is determined by the condition that the relative velocity between the triangles in contact has the direction which makes an angle $\Phi$ to the contact surface. It has been shown 


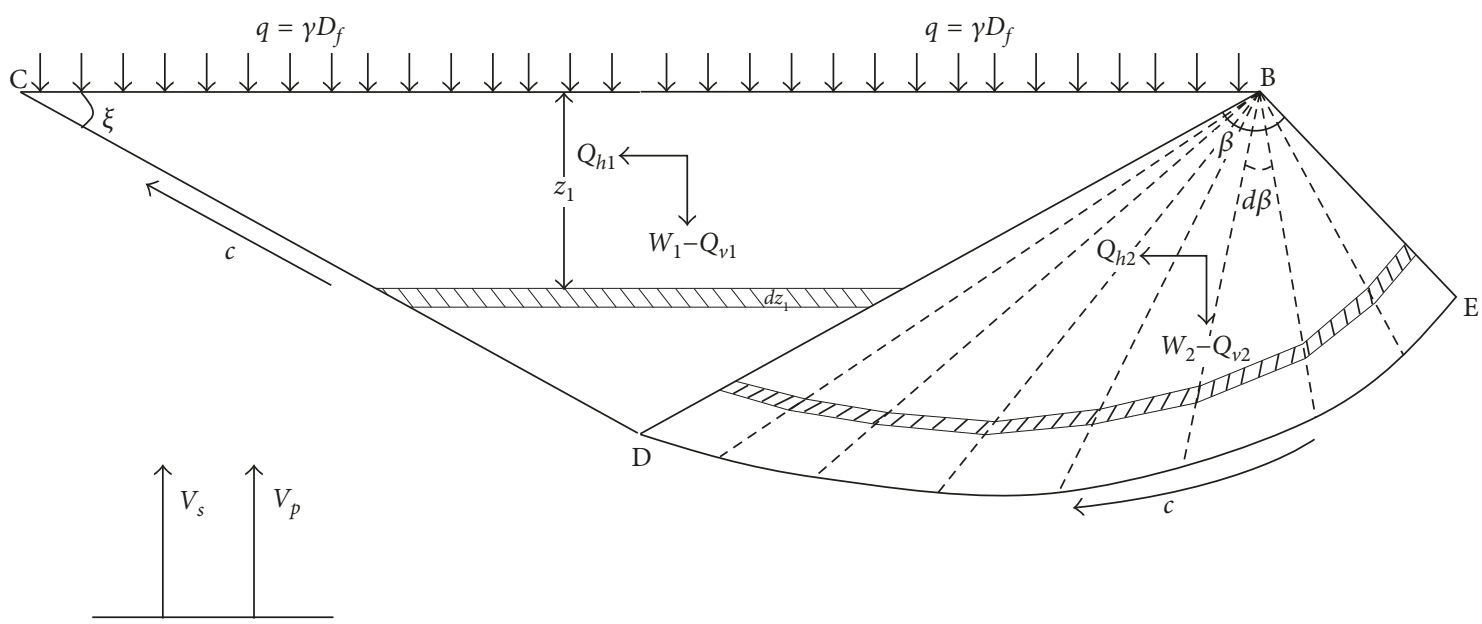

Figure 3: Log-spiral zone.

that the velocity $V$ of each triangle is $V_{1}=V_{0} e^{\theta \tan \phi}$. The log-spiral curve ED is assumed to be tangent to the line DE at $\mathrm{D}$; hence, there is no velocity discontinuity along the line BD. Finally, the triangular wedge BCD is assumed to be rigid, moving with velocity, $V_{2}=V(\beta)=V_{1} e^{\beta \tan \phi}$. Therefore, the velocities so determined constitute a kinematically admissible velocity field. Velocity hodograph of this composite failure mechanism is shown in Figure 1(b). Having established the velocity field of the kinematically admissible failure mechanism, the incremental external work done and the incremental internal energy dissipation are calculated following the procedure as mentioned in [42].

\subsection{Analysis of Bearing Capacity}

2.3.1. Elastic Wedge. Weight of the wedge ABE,

$$
W=\frac{\gamma}{2} B_{0}^{2} \frac{\sin \alpha \sin \rho}{\cos \phi}
$$

where $\rho=(\pi / 2)-(\alpha-\phi)$.

If the base of the wedge is subjected to harmonic horizontal and vertical seismic accelerations of amplitude $a_{h} g$ and $a_{v} g$, respectively, the acceleration at any depth $z$ and time $t$, below the top of the surface, can be expressed as

$$
\begin{aligned}
& a_{h}(z, t)=a_{h} \sin \omega\left(t-\frac{r_{0} \sin \rho-z}{V_{s}}\right), \\
& a_{v}(z, t)=a_{v} \sin \omega\left(t-\frac{r_{0} \sin \rho-z}{V_{p}}\right) .
\end{aligned}
$$

The mass of a thin element of the elastic wedge at depth $z$ is

$$
m(z)=\frac{\gamma}{g}\left(\frac{1}{\tan \alpha}+\frac{1}{\tan \rho}\right)\left(r_{0} \sin \rho-z\right) d z .
$$

The total horizontal and vertical inertia forces acting within the elastic zone can be expressed as follows:

$$
\begin{aligned}
Q_{h} & =\gamma k_{h}\left(\frac{1}{\tan \alpha}+\frac{1}{\tan \rho}\right) \int_{0}^{r_{0} \sin \rho}\left(r_{0} \sin \rho-z\right) \sin \omega\left(t-\frac{r_{0} \sin \rho-z}{V_{s}}\right) d z \\
& =\frac{\gamma B_{0}^{2} \lambda k_{h} \sin ^{2} \rho \sin ^{2} \alpha}{2 \pi r_{0} \sin \rho \cos ^{2} \phi}\left(\frac{1}{\tan \alpha}+\frac{1}{\tan \rho}\right)\left[\cos 2 \pi\left(\frac{t}{T}-\frac{r_{0} \sin \rho}{\lambda}\right)+\frac{r_{0} \sin \rho}{2 \pi \lambda}\left\{\sin 2 \pi\left(\frac{t}{T}-\frac{r_{0} \sin \rho}{\lambda}\right)-\sin 2 \pi \frac{t}{T}\right\}\right]=\frac{\gamma}{2} B_{0}^{2} q_{h}, \\
Q_{v} & =\gamma k_{v}\left(\frac{1}{\tan \alpha}+\frac{1}{\tan \rho}\right) \int_{0}^{r_{0} \sin \rho}\left(r_{0} \sin \rho-z\right) \sin \omega\left(t-\frac{r_{0} \sin \rho-z}{V_{p}}\right) d z \\
& =\frac{\gamma B_{0}^{2} \eta k_{v} \sin ^{2} \rho \sin ^{2} \alpha}{2 \pi r_{0} \sin \rho \cos ^{2} \phi}\left(\frac{1}{\tan \alpha}+\frac{1}{\tan \rho}\right)\left[\cos 2 \pi\left(\frac{t}{T}-\frac{r_{0} \sin \rho}{\eta}\right)+\frac{r_{0} \sin \rho}{2 \pi \eta}\left\{\sin 2 \pi\left(\frac{t}{T}-\frac{r_{0} \sin \rho}{\eta}\right)-\sin 2 \pi \frac{t}{T}\right\}\right]=\frac{\gamma}{2} B_{0}^{2} q_{v} .
\end{aligned}
$$


2.3.2. Passive Rankine Zone. Weight of the wedge BCD,

$$
W_{1}=\frac{\gamma}{2} \frac{B_{0}^{2} e^{2 \beta \tan \phi} \sin ^{2} \alpha \cos (\beta-\alpha+\phi)}{\cos \phi \sin \xi} .
$$
$z_{1}$ is

The mass of a thin element of the elastic wedge at depth

$$
\begin{aligned}
m\left(z_{1}\right)= & \frac{\gamma}{g}\left[\left\{\tan (\beta+\phi-\alpha)+\frac{1}{\tan (\beta-\alpha)}\right\}\right. \\
& \left.\times\left\{r_{0} e^{\beta \tan \phi} \cos (\beta+\phi-\alpha)-z\right\}\right] d z .
\end{aligned}
$$

The acceleration at any depth $z_{1}$ and time $t$, below the top of the surface, can be expressed as

$$
\begin{aligned}
& a_{h}\left(z_{1}, t\right)=a_{h} \sin \omega\left(t-\frac{r_{0} e^{\beta \tan \phi} \cos (\beta+\phi-\alpha)-z_{1}}{V_{s}}\right), \\
& a_{v}\left(z_{1}, t\right)=a_{v} \sin \omega\left(t-\frac{r_{0} e^{\beta \tan \phi} \cos (\beta+\phi-\alpha)-z_{1}}{V_{p}}\right) .
\end{aligned}
$$

The total horizontal and vertical inertia force acting within the passive Rankine zone can be expressed as follows:

$$
\begin{aligned}
Q_{h 1}= & \gamma k_{h}\left\{\tan (\beta+\phi-\alpha)+\frac{1}{\tan (\beta-\alpha)}\right\} \int_{0}^{r_{0} e^{\beta \tan \phi} \cos (\beta+\phi-\alpha)}\left[\left\{r_{0} e^{\beta \tan \phi} \cos (\beta+\phi-\alpha)-z\right\} \sin \omega\left(t-\frac{r_{0} e^{\beta \tan \phi} \cos (\beta+\phi-\alpha)-z_{1}}{V_{s}}\right)\right] d z_{1} \\
= & \frac{\gamma B_{0}^{2} \lambda k_{h} e^{2 \beta \tan \phi} \cos ^{2}(\beta+\phi-\alpha) \sin ^{2} \alpha}{2 \pi r_{0} e^{\beta \tan \phi} \cos (\beta+\phi-\alpha) \cos ^{2} \phi}\left\{\tan (\beta+\phi-\alpha)+\frac{1}{\tan (\beta-\alpha)}\right\}\left[\cos 2 \pi\left(\frac{t}{T}-\frac{r_{0} e^{\beta \tan \phi} \cos (\beta+\phi-\alpha)}{\lambda}\right)\right. \\
& \left.+\frac{r_{0} e^{\beta \tan \phi} \cos (\beta+\phi-\alpha)}{2 \pi \lambda}\left\{\sin 2 \pi\left(\frac{t}{T}-\frac{r_{0} e^{\beta \tan \phi} \cos (\beta+\phi-\alpha)}{\lambda}\right)-\sin 2 \pi \frac{t}{T}\right\}\right] \\
= & \frac{\gamma}{2} B_{0}^{2} q_{h 1},
\end{aligned}
$$

$$
\begin{aligned}
Q_{v 1}= & \gamma k_{v}\left\{\tan (\beta+\phi-\alpha)+\frac{1}{\tan (\beta-\alpha)}\right\} \int_{0}^{r_{0} e^{\beta \tan \phi} \cos (\beta+\phi-\alpha)}\left[\left\{r_{0} e^{\beta \tan \phi} \cos (\beta+\phi-\alpha)-z\right\} \sin \omega\left(t-\frac{r_{0} e^{\beta \tan \phi} \cos (\beta+\phi-\alpha)-z_{1}}{V_{p}}\right)\right] d z_{1} \\
= & \frac{\gamma B_{0}^{2} \eta k_{v} e^{2 \beta \tan \phi} \cos ^{2}(\beta+\phi-\alpha) \sin ^{2} \alpha}{2 \pi r_{0} e^{\beta \tan \phi} \cos (\beta+\phi-\alpha) \cos ^{2} \phi}\left\{\tan (\beta+\phi-\alpha)+\frac{1}{\tan (\beta-\alpha)}\right\}\left[\cos 2 \pi\left(\frac{t}{T}-\frac{r_{0} e^{\beta \tan \phi} \cos (\beta+\phi-\alpha)}{\eta}\right)\right. \\
& \left.+\frac{r_{0} e^{\beta \tan \phi} \cos (\beta+\phi-\alpha)}{2 \pi \eta}\left\{\sin 2 \pi\left(\frac{t}{T}-\frac{r_{0} e^{\beta \tan \phi} \cos (\beta+\phi-\alpha)}{\eta}\right)-\sin 2 \pi \frac{t}{T}\right\}\right] \\
= & \frac{\gamma}{2} B_{0}^{2} q_{v 1} .
\end{aligned}
$$

2.3.3. Log-Spiral Shear Zone. Weight of the log-spiral shear zone BDE,

$$
W_{2}=\frac{1}{2} \int_{0}^{\beta} r_{0}^{2} d \theta=\frac{r_{0}^{2}\left(e^{2 \beta \tan \phi}-1\right)}{4 \tan \phi}=\frac{B_{0}^{2} \sin ^{2} \alpha\left(e^{2 \beta \tan \phi}-1\right)}{2 \sin 2 \phi} .
$$

The log-spiral zone BDE is divided into " $n$ " number of slices which makes the angle of $\log$-spiral center $\beta$ into " $n$ " number of $d \beta$ angles, that is, $\beta=n d \beta$, as shown in Figure 4.

Mass of strip on the $i$ th slice of the log-spiral zone BDE,

$$
m(z)_{i}=\frac{\gamma}{g} \frac{2 \pi d \beta}{360^{\circ} \sin ^{2}(\rho+(i-0.5) d \beta)} \int_{0}^{H_{i}} z_{i}(d z)_{i},
$$

where $H_{i}=\left(r_{0} / 2\right)\left(e^{(i-1) d \beta \tan \phi}+e^{i d \beta \tan \phi}\right) \sin (\rho+(i-0.5) d \beta)$.

The acceleration at any depth $z_{i}$ and time $t$ of any $i$ th slice of the log-spiral shear zone, below the top of the surface, can be expressed as

$$
\begin{aligned}
& a_{h}(z, t)_{i}=k_{h} g \sin \omega\left(t-\frac{H_{i}-z_{i}}{V_{s}}\right), \\
& a_{v}(z, t)_{i}=k_{v} g \sin \omega\left(t-\frac{H_{i}-z_{i}}{V_{p}}\right) .
\end{aligned}
$$

The total horizontal and vertical inertia force acting within this $i$ th slice can be expressed as follows: 


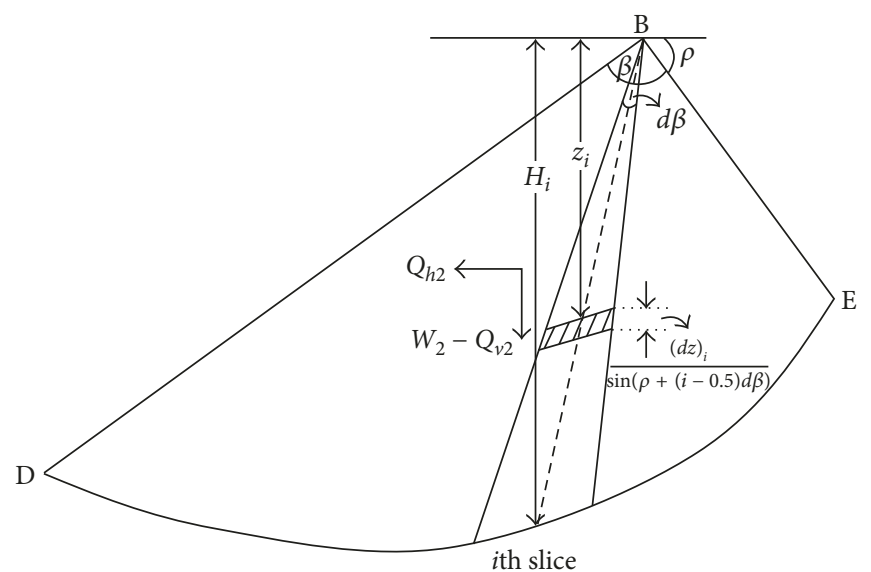

FIgURE 4: Generalized slice and centre of gravity of the log-spiral zone.

$$
\begin{aligned}
\left(Q_{h}\right)_{i} & =\frac{2 \pi \gamma d \beta k_{h}}{360^{\circ} \sin ^{2}(\rho+(i-0.5) d \beta)} \int_{0}^{H_{i}} z_{i} \sin \omega\left(t-\frac{H_{i}-z_{i}}{V_{s}}\right)(d z)_{i} \\
& =\frac{\gamma d \beta k_{h} \lambda B_{0}^{2} \sin ^{2} \alpha\left(e^{(i-1) d \beta \tan \phi}+e^{i d \beta \tan \phi}\right)^{2}}{360^{\circ} * 4 \mathrm{H}_{i} \cos ^{2} \phi}\left[\frac{\lambda}{H_{i} 2 \pi}\left\{\sin 2 \pi \frac{t}{T}-\sin 2 \pi\left(\frac{t}{T}-\frac{H_{i}}{\lambda}\right)\right\}-\cos 2 \pi \frac{t}{T}\right] \\
& =\frac{\gamma}{2} B_{0}^{2} q_{h 2}\left(e^{(i-1) d \beta \tan \phi}+e^{i d \beta \tan \phi}\right)^{2}, \\
\left(Q_{v}\right)_{i} & =\frac{2 \pi \gamma d \beta k_{v}}{360^{\circ} \sin ^{2}(\rho+(i-0.5) d \beta)} \int_{0}^{H_{i}} z_{i} \sin \omega\left(t-\frac{H_{i}-z_{i}}{V_{p}}\right)(d z)_{i} \\
& =\frac{\gamma d \beta k_{v} \eta B_{0}^{2} \sin ^{2} \alpha\left(e^{(i-1) d \beta \tan \phi}+e^{i d \beta \tan \phi}\right)^{2}}{360^{\circ} * 4 \mathrm{H}_{i} \cos ^{2} \phi}\left[\frac{\eta}{H_{i} 2 \pi}\left\{\sin 2 \pi \frac{t}{T}-\sin 2 \pi\left(\frac{t}{T}-\frac{H_{i}}{\eta}\right)\right\}-\cos 2 \pi \frac{t}{T}\right] \\
& =\frac{\gamma}{2} B_{0}^{2} q_{v 2}\left(e^{(i-1) d \beta \tan \phi}+e^{i d \beta \tan \phi}\right)^{2} .
\end{aligned}
$$

Now, the total horizontal and vertical inertia force acting on log-spiral shear zone is expressed as

$$
Q_{h 2}=\sum_{i=1}^{n}\left(Q_{h}\right)_{i}=\frac{\gamma}{2} B_{0}^{2} q_{h 2} \sum_{i=1}^{n}\left(e^{(i-1) d \beta \tan \phi}+e^{i d \beta \tan \phi}\right)^{2},
$$

$$
Q_{v 2}=\sum_{i=1}^{n}\left(Q_{v}\right)_{i}=\frac{\gamma}{2} B_{0}^{2} q_{v 2} \sum_{i=1}^{n}\left(e^{(i-1) d \beta \tan \phi}+e^{i d \beta \tan \phi}\right)^{2} .
$$

The incremental external works due to the foundation load $P$, surcharge load $q$, the weight of the soil wedges $\mathrm{ABE}$, $\mathrm{BCD}$, and $\mathrm{BDE}$, and their corresponding inertial forces are

$$
\begin{aligned}
W_{B C D} & =-\frac{\gamma}{4} B_{0}^{2} \frac{e^{3 \beta \tan \phi} \sin ^{2} \alpha \sin 2(\beta-\alpha+\phi)}{\cos \phi \sin \xi} V_{1}, \\
W_{Q} & =-\gamma D_{f} \frac{B_{0} \sin \alpha e^{2 \beta \tan \phi}}{\sin \xi}\left[\left\{-k_{h} \sin 2 \pi\left(\frac{t}{T}-\frac{H}{\lambda}\right) \cos (\beta-\alpha+\phi)\right\}+\left\{\left(1-k_{v} \sin 2 \pi\left(\frac{t}{T}-\frac{H}{\eta}\right)\right) \sin (\beta-\alpha+\phi)\right\}\right] V_{1},
\end{aligned}
$$

$$
\begin{aligned}
W_{B D E} & =-\frac{\gamma}{2} \int_{0}^{\beta} r_{0}^{2} d \theta V_{\theta} \sin (\theta+\phi-\alpha) \\
& =-\frac{\gamma}{2} B_{0}^{2} \frac{\sin ^{2} \alpha}{\cos ^{2} \phi\left(1+9 \tan ^{2} \phi\right)}\left[3 \tan \phi\left\{e^{3 \beta \tan \phi} \sin (\beta+\phi-\alpha)-\sin (\phi-\alpha)\right\}-e^{3 \beta \tan \phi} \cos (\beta+\phi-\alpha)+\cos (\phi-\alpha)\right] V_{1},
\end{aligned}
$$




$$
\begin{aligned}
W_{\mathrm{Q} h}= & Q_{h} V_{1} \cos (\alpha-\phi) \\
W_{\mathrm{Q} v}= & -Q_{v} V_{1} \sin (\alpha-\phi) \\
W_{\mathrm{Q} h 1}= & Q_{h 1} V_{1} e^{\beta \tan \phi} \cos (\beta-\alpha+\phi), \\
W_{\mathrm{Q} v 1}= & Q_{v 1} V_{1} e^{\beta \tan \phi} \sin (\beta-\alpha+\phi) \\
W_{\mathrm{Q} h 2}= & \frac{\gamma}{2} B_{0}^{2} q_{h 2} \sum_{i=1}^{n}\left[\left(e^{(i-1) d \beta \tan \phi}+e^{i d \beta \tan \phi}\right)^{2} \int_{(i-1) d \beta}^{i d \beta} V_{\theta} \cos (\theta+\phi-\alpha) d \theta\right] \\
= & \frac{\gamma}{2} B_{0}^{2} q_{h 2} \frac{V_{1}}{(1+\tan \phi)} \sum_{i=n}^{n}\left[( e ^ { ( i - 1 ) d \beta \operatorname { t a n } \phi } + e ^ { i d \beta \operatorname { t a n } \phi } ) ^ { 2 } \left\{e^{i d \beta \tan \phi}(\sin (i d \beta+\phi-\alpha)+\tan \phi \cos (i d \beta+\phi-\alpha))\right.\right. \\
& \left.\left.-e^{(i-1) d \beta \tan \phi}(\sin ((i-1) d \beta+\phi-\alpha)+\tan \phi \cos ((i-1) d \beta+\phi-\alpha))\right\}\right] \\
W_{\mathrm{Q} v 2}= & \frac{\gamma}{2} B_{0}^{2} q_{v 2} \sum_{i=1}^{n}\left[\left(e^{(i-1) d \beta \tan \phi}+e^{i d \beta \tan \phi}\right)^{2} \int_{(i-1) d \beta}^{i d \beta} V_{\theta} \sin (\theta+\phi-\alpha) d \theta\right] \\
= & \frac{\gamma}{2} B_{0}^{2} q_{v 2} \frac{V_{1}}{\left(1+\tan ^{2} \phi\right)} \sum_{i=1}^{n}\left[( e ^ { ( i - 1 ) d \beta \operatorname { t a n } \phi } + e ^ { i d \beta \operatorname { t a n } \phi } ) ^ { 2 } \left\{e^{i d \beta \tan \phi}(-\cos (i d \beta+\phi-\alpha)+\tan \phi \sin (i d \beta+\phi-\alpha))\right.\right. \\
& \left.\left.-e^{(i-1) d \beta \tan \phi}(-\cos ((i-1) d \beta+\phi-\alpha)+\tan \phi \sin ((i-1) d \beta+\phi-\alpha))\right\}\right]
\end{aligned}
$$

The incremental internal energy dissipation along the velocity discontinuities $\mathrm{AE}$ and $\mathrm{CD}$ and the radial line $\mathrm{DE}$ is

$$
\begin{aligned}
& D_{\mathrm{AE}}=c \mathrm{ACV}_{1} \cos \phi=c B_{0} \sin \rho V_{1}, \\
& D_{\mathrm{CD}}=c \mathrm{CDV}_{2} \cos \phi=\frac{c B_{0} e^{2 \beta \tan \phi} \sin \alpha \cos (\beta-\alpha+\phi)}{\sin (\beta-\alpha)} V_{1}, \\
& D_{\mathrm{DE}}=c \int_{0}^{\beta} r_{0} d \theta V_{\theta} \cos \phi=\frac{c B_{0} \sin \alpha\left(e^{2 \beta \tan \phi}-1\right)}{2 \tan \phi} V_{1}
\end{aligned}
$$

Equating the work expended by the external loads to the power dissipated internally for a kinematically admissible velocity field, we can get the expression of pseudodynamic ultimate bearing capacity of shallow strip footing. The classical ultimate bearing capacity equation of shallow strip footing,

$$
P_{L}=Q_{\text {ult }}=c N_{c}+\gamma D_{f} N_{q}+0.5 \gamma B_{0} N_{\gamma} .
$$

After solving the above equations, the simplified form of the bearing capacity coefficients is as follows:

$$
\begin{aligned}
N_{c}= & {\left[\frac{\sin \alpha}{2 \tan \phi}\left(e^{2 \beta \tan \phi}-1\right)+\cos (\alpha-\phi)+\frac{e^{2 \beta \tan \phi} \sin \alpha \cos (\beta-\alpha+\phi)}{\sin (\beta-\alpha)}\right], } \\
N_{q}= & {\left[\frac{\sin \alpha e^{2 \beta \tan \phi}}{\sin \xi}\left[\left\{-k_{h} \sin 2 \pi\left(\frac{t}{T}-\frac{H}{\lambda}\right) \cos (\beta-\alpha+\phi)\right\}+\left\{\left(1-k_{v} \sin 2 \pi\left(\frac{t}{T}-\frac{H}{\eta}\right)\right) \sin (\beta-\alpha+\phi)\right\}\right],\right.} \\
N_{\gamma}= & {\left[\frac{\sin ^{2} \alpha}{\cos ^{2} \phi\left(1+9 \tan ^{2} \phi\right)}\left[3 \tan \phi\left\{e^{3 \beta \tan \phi} \sin (\beta+\phi-\alpha)-\sin (\phi-\alpha)\right\}-e^{3 \beta \tan \phi} \cos (\beta+\phi-\alpha)+\cos (\phi-\alpha)\right]\right.} \\
& -\frac{\sin \alpha \sin 2 \rho}{2 \cos \phi}+\frac{e^{3 \beta \tan \phi} \sin ^{2} \alpha \sin 2(\beta-\alpha+\phi)}{2 \cos \phi \sin \xi}-q_{h} \cos (\alpha-\phi)+q_{v} \sin (\alpha-\phi)-q_{h 1} e^{\beta \tan \phi} \cos (\beta+\phi-\alpha)-q_{v 1} e^{\beta \tan \phi} \sin (\beta+\phi-\alpha) \\
& -\frac{\sum_{i=1}^{n}\left(e^{(i-1) d \beta \tan \phi}+e^{i d \beta \tan \phi}\right)^{2}}{\left(1+\tan ^{2} \phi\right)}\left[q _ { h 2 } \sum _ { i = 1 } ^ { n } \left\{e^{i d \beta \tan \phi}(\sin (i d \beta+\phi-\alpha)+\tan \phi \cos (i d \beta+\phi-\alpha))-e^{(i-1) d \beta \tan \phi}(\sin ((i-1) d \beta+\phi-\alpha)\right.\right. \\
& +\tan \phi \cos ((i-1) d \beta+\phi-\alpha))\}+q_{v 2} \sum_{i=1}^{n}\left\{e^{i d \beta \tan \phi}(\sin (i d \beta+\phi-\alpha)+\tan \phi \cos (i d \beta+\phi-\alpha))\right. \\
& \left.\left.-e^{(i-1) d \beta \tan \phi}(\sin ((i-1) d \beta+\phi-\alpha)+\tan \phi \cos ((i-1) d \beta+\phi-\alpha))\right\}\right] .
\end{aligned}
$$


An attampt is made to present 'single seismic bearing capacity coefficient' for simultaneous resistance of unit weight, surcharge and cohesion as in a practical situation, there will be a single failure mechanism for the simultaneous resistance of unit weight, surcharge, and cohesion. So, we get

$$
P_{L}=\frac{\gamma}{2} B_{0} N
$$

After simplification of equations, the expression of $N$ is given below.

$$
\begin{aligned}
N= & {\left[\frac{\sin ^{2} \alpha}{\cos ^{2} \phi\left(1+9 \tan ^{2} \phi\right)}\left[3 \tan \phi\left\{e^{3 \beta \tan \phi} \sin (\beta+\phi-\alpha)-\sin (\phi-\alpha)\right\}-e^{3 \beta \tan \phi} \cos (\beta+\phi-\alpha)+\cos (\phi-\alpha)\right]\right.} \\
& +\frac{e^{3 \beta \tan \phi} \sin ^{2} \alpha \sin 2(\beta-\alpha+\phi)}{2 \cos \phi \sin \xi}-\frac{\sin \alpha \sin 2 \rho}{2 \cos \phi}+2 \frac{D_{f}}{B_{0}} \frac{\sin \alpha e^{2 \beta \tan \phi}}{\sin \xi}\left[\left\{-k_{h} \sin 2 \pi\left(\frac{t}{T}-\frac{H}{\lambda}\right) \cos (\beta-\alpha+\phi)\right\}\right. \\
& \left.+\left\{\left(1-k_{v} \sin 2 \pi\left(\frac{t}{T}-\frac{H}{\eta}\right)\right) \sin (\beta-\alpha+\phi)\right\}\right]-q_{h} \cos (\alpha-\phi)+q_{v} \sin (\alpha-\phi)-q_{h 1} e^{\beta \tan \phi} \cos (\beta+\phi-\alpha) \\
& -q_{v 1} e^{\beta \tan \phi} \sin (\beta+\phi-\alpha)-\frac{\sum_{i=1}^{n}\left(e^{(i-1) d \beta \tan \phi}+e^{i d \beta \tan \phi}\right)^{2}}{\left(1+\tan ^{2} \phi\right)}\left[q_{h 2} \sum_{i=1}^{n} e^{i d \beta \tan \phi}(\sin (i d \beta+\phi-\alpha)\right. \\
& +\tan \phi \cos (i d \beta+\phi-\alpha))-e^{(i-1) d \beta \tan \phi}(\sin ((i-1) d \beta+\phi-\alpha)+\tan \phi \cos ((i-1) d \beta+\phi-\alpha)) \\
& +q_{v 2} \sum_{i=1}^{n}\left\{e^{i d \beta \tan \phi}(\sin (i d \beta+\phi-\alpha)+\tan \phi \cos (i d \beta+\phi-\alpha))-e^{(i-1) d \beta \tan \phi}(\sin ((i-1) d \beta+\phi-\alpha)\right. \\
& +\tan \phi \cos ((i-1) d \beta+\phi-\alpha))\}]+\frac{2 c}{\gamma B_{0}}\left\{\frac{\sin \alpha}{2 \tan \phi}\left(e^{2 \beta \tan \phi}-1\right)+\cos (\alpha-\phi)+\frac{e^{2 \beta \tan \phi} \sin \alpha \cos (\beta-\alpha+\phi)}{\sin (\beta-\alpha)}\right.
\end{aligned}
$$

Here, $N$ is the single pseudodynamic bearing capacity coefficient of shallow strip footing under seismic loading condition. In this formulation, the objective function pseudodynamic bearing capacity coefficient depends on these $\Phi, c, \alpha, \beta, t / T, k_{h}, k_{v}, H / \lambda$, and $H / \eta$ functions. For a particular soil and seismic condition, all other terms are constant except $\alpha, \beta$, and $t / T$. So, optimization of pseudodynamic bearing capacity coefficient is done with respect to $\alpha, \beta$, and $t / T$ using the HSOS algorithm. The advantage of this HSOS algorithm is that it can improve the searching capability of the algorithm for attaining the global optimization. Here, the optimum value of $N$ is represented as $N_{\gamma \mathrm{e}}$. Now, pseudodynamic ultimate bearing capacity,

$$
Q_{\text {ult }}=0.5 \gamma B_{0} N_{\gamma e}
$$

\section{The Hybrid Symbiosis Organisms Search Algorithm}

The hybrid symbiosis organisms search (HSOS) algorithm is a recently developed hybrid optimization algorithm which is used to solve this pseudodynamic bearing capacity of shallow strip footing minimal optimization problem.

3.1. The Symbiosis Organisms Search Algorithm. Symbiosis organisms search (SOS) algorithm is a population-based iterative global optimization algorithm for solving global optimization problems, proposed by Cheng and Prayogo [33].
This algorithm is based on the basic concept of symbiotic relationships among the organisms in nature (ecosystem). Three types of symbiotic relationships are occurring in an ecosystem. These are mutualism relationship, commensalism relationship, and parasitism relationship. Mutualism relationship describes the relationship where both organisms get benefits from the interaction. Commensalism relationship is a symbiotic relationship between two different organisms where one organism gets the benefit and the other is not significantly affected. In the symbiotic parasitism relationship, one organism gets the benefit and the other is harmed, but not always killed. Based on the concept of three relationships, the SOS algorithm is executed. In the SOS algorithm, a group of organisms in an ecosystem is considered as a population size of the solution. Each organism is analogous to one solution vector, and the fitness value of each organism represents the degree of adaptation to the desired objective. Initially, a set of organisms in the ecosystem is generated randomly within the search region. The new candidate solution is generated through the biological interaction between two organisms in the ecosystem which contains the mutualism, commensalism, and parasitism phases, and the process of interaction is continued until the termination criterion is satisfied. A detailed description of SOS algorithm can be seen in [33].

3.2. The Simple Quadratic Interpolation (SQI) Method. In this section, the three-point quadratic interpolation is discussed. 
Considering the two organisms $\operatorname{Org}_{j}$ and $\operatorname{Org}_{k}$, where $\operatorname{Org}_{j}=$ $\left(\operatorname{org}_{j}^{1}, \operatorname{org}_{j}^{2}, \operatorname{org}_{j}^{3}, \ldots, \operatorname{org}_{j}^{D}\right)$ and $\operatorname{Org}_{k}=\left(\operatorname{org}_{k}^{1}, \operatorname{org}_{k}^{2}, \operatorname{org}_{k}^{3}, \ldots\right.$, $\operatorname{org}_{k}^{D}$ ) from the ecosystem, the organism Org $\operatorname{Org}_{i}$ is updated according to the three-point quadratic interpolation [40]. The three-point approximate minimal point for organism $\mathrm{Org}_{i}$ is determined by the following equation:

$$
\overline{\mathrm{Org}}_{i}^{m}=0.5 \frac{\left(\left(\mathrm{Org}_{i}^{m}\right)^{2}-\left(\mathrm{Org}_{j}^{m}\right)^{2}\right) f_{k}+\left(\left(\mathrm{Org}_{j}^{m}\right)^{2}-\left(\mathrm{Org}_{k}^{m}\right)^{2}\right) f_{i}+\left(\left(\mathrm{Org}_{k}^{m}\right)^{2}-\left(\mathrm{Org}_{i}^{m}\right)^{2}\right) f_{j}}{\left(\mathrm{Org}_{i}^{m}-\mathrm{Org}_{l}^{m}\right) f_{k}+\left(\mathrm{Org}_{j}^{m}-\mathrm{Org}_{k}^{m}\right) f_{i}+\left(\mathrm{Org}_{k}^{m}-\mathrm{Org}_{i}^{m}\right) f_{j}}
$$

where $m=1,2,3, \ldots, D$.

The SQI is intended to enhance the entire search capability of the algorithm. Here, $f_{i}, f_{j}$, and $f_{k}$ are the fitness values of $i$ th, $j$ th, and $k$ th organisms, respectively.

3.3. The Hybrid Symbiosis Organisms Search Algorithm. In the development of heuristic global optimization algorithm, the balance of exploration and exploitation capability plays a major role [43], where "Exploration is the process of visiting entirely new regions of a search space, whilst exploitation is the process of visiting those regions of a search space within the neighborhood of previously visited points" [43]. As discussed above, the SQI method may be used for the better exploration when executing the optimization process. On the other hand, Cheng and Prayoga [33] have elaborately discussed the better exploitation ability of SOS for global optimization. To balance the exploration capability of SQI and the exploitation potential of SOS, the hybrid symbiosis organisms search (HSOS) algorithm has been proposed. This hybrid method can increase the robustness as well as the searching capability of the algorithm for attaining the global optimization. By incorporating the SQI into the SOS algorithm, the HSOS algorithm is developed and the flowchart of the HSOS algorithm is shown in Figure 5. The HSOS algorithm is able to explore the new search region with the SOS algorithm and to exploit the population information with the SQI.

If an organism is going to an infeasible region, then the organism is reflected back to the feasible region using the following equation [44]:

$$
\operatorname{Org}_{i}= \begin{cases}\mathrm{UB}_{i}+\operatorname{rand}(0,1) *\left(\mathrm{UB}_{i}-\mathrm{LB}_{i}\right) & \text { if } \mathrm{Org}_{i}<\mathrm{LB}_{i} \\ \mathrm{UB}_{i}-\operatorname{rand}(0,1) *\left(\mathrm{UB}_{i}-\mathrm{LB}_{i}\right) & \text { if } \mathrm{Org}_{i}>\mathrm{UB}_{i}\end{cases}
$$

where $\mathrm{LB}_{i}$ and $\mathrm{UB}_{i}$ are, respectively, the lower and upper bounds of the $i$ th organism.

The algorithmic steps of hsos are given below:

Step 1. Ecosystem initialization: initialize the algorithm parameters and ecosystem organisms and evaluate the fitness value for each corresponding organism.

Step 2. Main loop.

Step 2.1. Mutualism phase: select one organism $\mathrm{Org}_{j}$ randomly from the ecosystem. The organism $\operatorname{Org}_{i}$ intersects with the organism $\operatorname{Org}_{j}$ and then they try to improve the survival capabilities in the ecosystem. The new organism for each of $\mathrm{Org}_{i}$ and $\mathrm{Org}_{j}$ is calculated by the following equations:

$$
\begin{gathered}
\operatorname{Org}_{i}^{\text {new }}=\operatorname{Org}_{i}+\operatorname{rand}(0,1) *\left(\operatorname{Org}_{\text {best }}-\text { Mutual }_{\text {Vector }} * B F 1\right), \\
\operatorname{Org}_{j}^{\text {new }}=\operatorname{Org}_{j}+\operatorname{rand}(0,1) *\left(\operatorname{Org}_{\text {best }}-\text { Mutual }_{\text {Vector }} * B F 2\right),
\end{gathered}
$$

where Mutual $\mathrm{Vector}=\left(\mathrm{Org}_{i}+\mathrm{Org}_{j}\right) / 2$. Here, BF1 and BF2 are called the benefit factors, the value of which be either 1 or 2 . The level of benefits of the organism represents these factors, that is, whether an organism gets, respectively, partial or full benefit from the interaction. $\mathrm{Org}_{\text {best }}$ is the best organism in the ecosystem. Mutual ${ }_{\text {Vector }}$ represents the relationship characteristic between the organisms $\operatorname{Org}_{i}$ and $\operatorname{Org}_{j}$.

Step 2.2. Commensalism phase: between the interaction of the organisms $\mathrm{Org}_{i}$ and $\mathrm{Org}_{j}$, the organism $\mathrm{Org}_{i}$ gets benefit by the organism $\mathrm{Org}_{j}$ and try to improve the beneficial advantage in the ecosystem to the higher degree of adaption. The new organism $\mathrm{Org}_{i}$ is determined by the following equation:

$$
\operatorname{Org}_{i}^{\text {new }}=\operatorname{Org}_{i}+\operatorname{rand}(-1,1) *\left(\operatorname{Org}_{\text {best }}-\operatorname{Org}_{j}\right)
$$

where $i \neq j$ and $\operatorname{Org}_{\text {best }}$ is the best organism in the ecosystem.

Step 2.3. Parasitism phase: by duplicating randomly selected dimensions of the organism $\mathrm{Org}_{i}$, an artificial parasite (Parasite_Vector) is created. From the ecosystem, another organism $\mathrm{Org}_{j}$ is selected randomly that is treated as a host to the Parasite_Vector. If the objective function value of the Parasite_Vector is better than the organism $\operatorname{Org}_{j}$, it can kill the organism $\mathrm{Org}_{j}$ and adopt its position in the ecosystem. If the objective function value of $\mathrm{Org}_{j}$ is better than the Parasite_Vector, $\mathrm{Org}_{j}$ will have resistance to the parasite and the Parasite_Vector will not be able to reside in that ecosystem.

Step 2.4. Simple quadratic interpolation: the two organisms $\operatorname{Org}_{j}$ and $\operatorname{Org}_{k}(j \neq \mathrm{k})$ are selected randomly from the ecosystem, and then the organism $\operatorname{Org}_{i}$ is updated by quadratic interpolation passing through these three organisms which can be expressed by (40).

Step 3. If the stopping criteria are not satisfied to go to Step 2, then it will proceed until the best objective function value is obtained. 


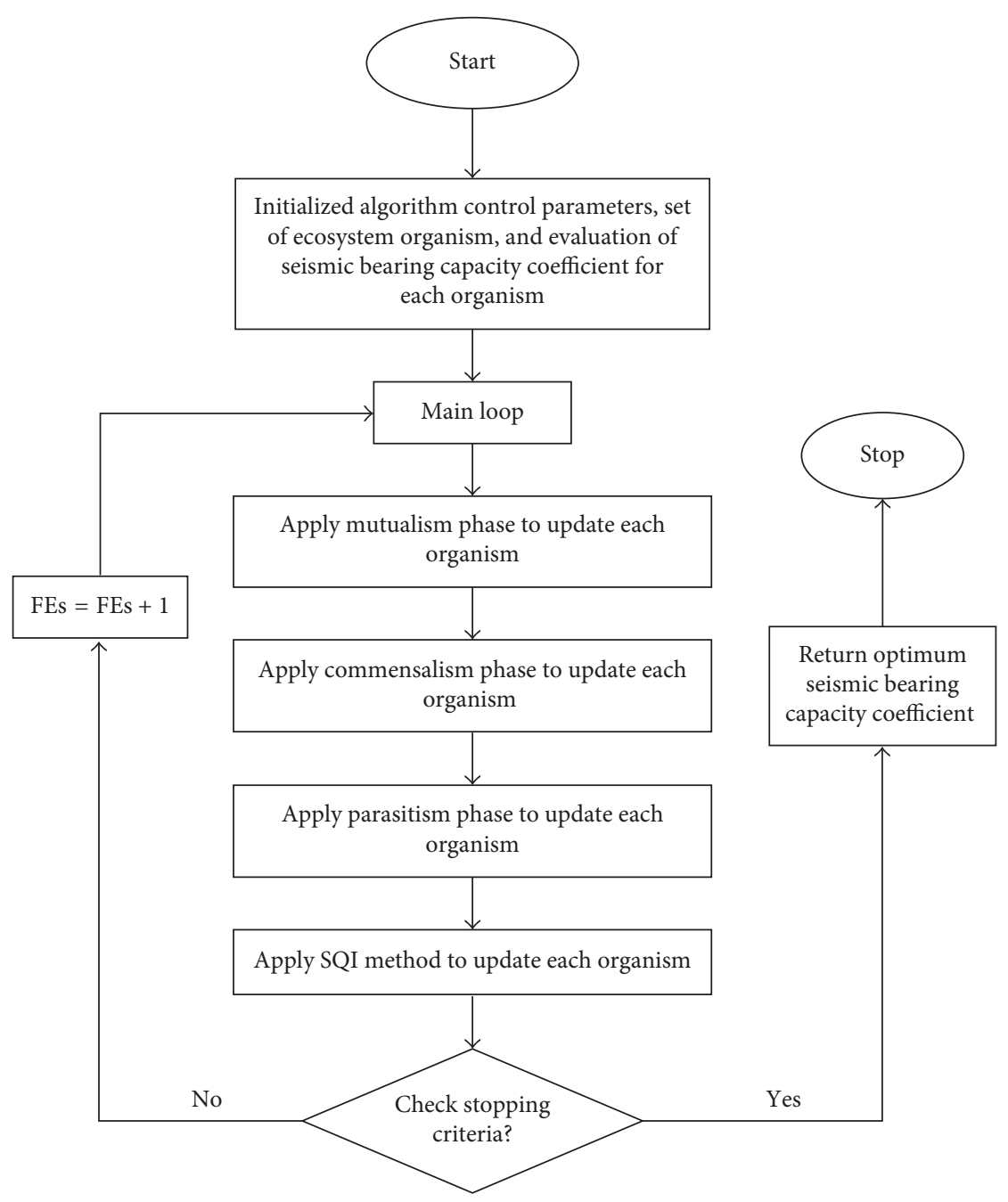

FIgURE 5: Flowchart of the HSOS algorithm.

\section{Discussion on Results Obtained by the HSOS Algorithm}

The pseudodynamic bearing capacity coefficient $\left(N_{\gamma \mathrm{e}}\right)$ has been optimized using the HSOS algorithm with respect to $\alpha$, $\beta$, and $t / T$ variables. The algorithm was performed with 1000 fitness evaluations, 30 independent runs, and 50 eco-sizes. The best result has been taken among these 30 results. This optimized single seismic bearing capacity coefficient $\left(N_{\gamma \mathrm{e}}\right)$ is presented in Tables 1 and 2 for static and seismic conditions $\left(k_{h}=0.1,0.2\right.$, and 0.3$)$, respectively, which can be used by the field engineers in earthquake-prone areas for the simultaneous resistance of unit weight, surcharge, and cohesion.

4.1. Parametric Study. In this section, a brief parametric study and a comparative study have been presented. The effect of soil friction angle $(\Phi)$, depth factor $\left(D_{f} / B_{0}\right)$, cohesion factor $\left(2 c / \gamma B_{0}\right)$, and seismic accelerations $\left(k_{h}\right.$ and $\left.k_{v}\right)$ on normalized reduction factor $\left(N_{\gamma \mathrm{e}} / N_{\gamma \mathrm{s}}\right)$ is discussed. Normalized reduction factor $\left(N_{\gamma \mathrm{e}} / N_{\gamma \mathrm{s}}\right)$ is the ratio of optimized seismic and static bearing capacity coefficient. The variations of parameters are as follows: $\Phi=20^{\circ}, 30^{\circ}$, and $40^{\circ} ; k_{h}=0.1,0.2$, and $0.3 ; k_{v}=0$,
TABLE 1: Static condition.

\begin{tabular}{cccccc}
\hline \multirow{2}{*}{$\Phi$} & $2 c / \gamma B_{0}$ & \multicolumn{5}{c}{$D_{f} / B_{0}$} \\
& 0.25 & 0.5 & 0.75 & 1 \\
\hline \multirow{2}{*}{$20^{\circ}$} & 0.25 & 8.349 & 11.756 & 15.087 & 18.377 \\
& 0.5 & 11.175 & 14.488 & 17.769 & 21.029 \\
& 0 & 30.439 & 17.155 & 20.407 & 23.649 \\
$30^{\circ}$ & 0.25 & 35.903 & 45.497 & 54.975 & 64.391 \\
& 0.5 & 41.263 & 50.771 & 60.189 & 69.557 \\
& 0 & 144.24 & 178.37 & 211.78 & 244.89 \\
$40^{\circ}$ & 0.25 & 157.48 & 191.17 & 224.5 & 257.5 \\
& 0.5 & 170.47 & 203.94 & 237.1 & 270.1 \\
\hline
\end{tabular}

$k_{h} / 2$, and $k_{h} ; 2 c / \gamma B_{0}=0,0.25$, and 0.5 ; and $D_{f} / B_{0}=0.25,0.75$, 0.5 , and 1 . A detailed comparative study with other available previous research is also discussed in this section.

4.1.1. Effect on $N_{\gamma e} / N_{\gamma s}$ due to Variation of $\Phi$. Figure 6 shows the variations of the normalized reduction factor $\left(N_{\gamma \mathrm{e}} / N_{\gamma \mathrm{s}}\right)$ with respect to horizontal seismic acceleration $\left(k_{h}\right)$ at different soil friction angles $\left(\Phi=20^{\circ}, 30^{\circ}\right.$, and $\left.40^{\circ}\right)$ at 
TABLe 2: Pseudodynamic bearing capacity coefficient $\left(N_{\gamma \mathrm{e}}\right)$ for $k_{h}=0.1,0.2$, and 0.3 .

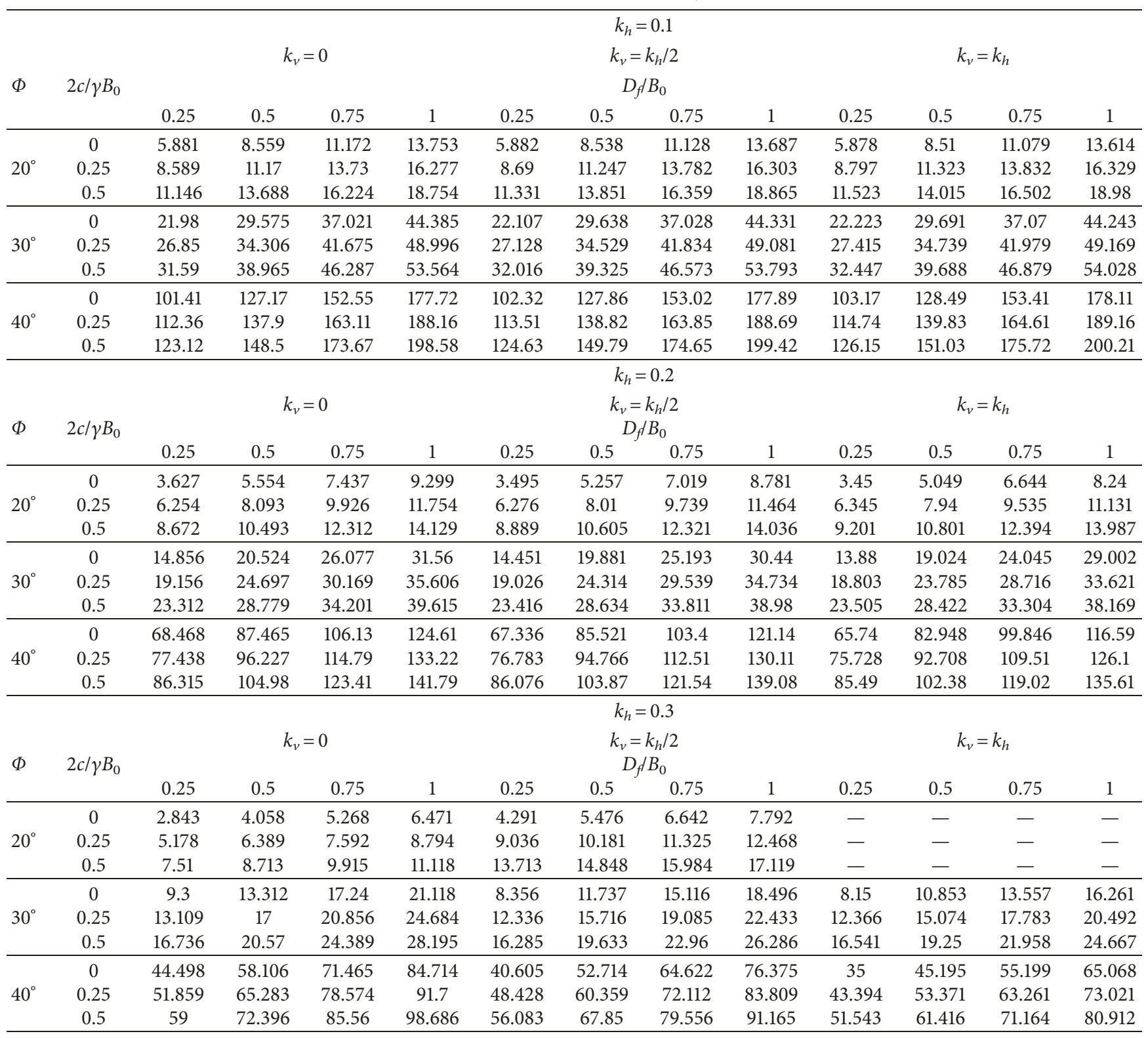

$2 c / \gamma B_{0}=0.25, D_{f}=0.5$, and $k_{v}=k_{h} / 2$. It is seen that the normalized reduction factor $\left(N_{\gamma \mathrm{e}} / N_{\gamma \mathrm{s}}\right)$ increases with increase in soil friction angle $(\Phi)$. Due to an increase in $\Phi$, the internal resistance of the soil particles will be increased, which resembles the fact that there is an increase in the seismic bearing capacity factor.

4.1.2. Effect on $N_{\gamma \mathrm{e}} / N_{\gamma \mathrm{s}}$ due to Variation of $2 c / \gamma B_{0}$. Figure 7 shows the variations of the normalized reduction factor $\left(N_{\gamma \mathrm{e}} / N_{\gamma \mathrm{s}}\right)$ with respect to seismic acceleration $\left(k_{h}\right)$ at different cohesion factors $\left(2 c / \gamma B_{0}=0,0.25\right.$, and 0.5$)$ at $\Phi=30^{\circ}$, $D_{f} / B_{0}=0.5$, and $k_{v}=k_{h} / 2$. It is seen that the normalized reduction factor $\left(N_{\gamma \mathrm{e}} / N_{\gamma \mathrm{s}}\right)$ increases with an increase in the cohesion factor $\left(2 c / \gamma B_{0}\right)$. Due to an increase in cohesion, the seismic bearing capacity factor will be increased as the increase in cohesion causes an increase in intermolecular attraction among the soil particle, which offers more resistance against the shearing failure of the foundation.

4.1.3. Effect on $N_{\gamma \mathrm{e}} / N_{\gamma \mathrm{s}}$ due to Variation of $D_{f} / B_{0}$. Figure 8 shows the variations of the normalized reduction factor $\left(N_{\gamma \mathrm{e}} / N_{\gamma \mathrm{s}}\right)$ with respect to seismic acceleration $\left(k_{h}\right)$ for different depth factors $\left(D_{f} / B_{0}=0.25,0.5\right.$, and 1$)$ at $\Phi=30^{\circ}, 2 c / \gamma B_{0}=$ 0.25 , and $k_{v}=k_{h} / 2$. It is seen that the normalized reduction factor $\left(N_{\gamma \mathrm{e}} / N_{\gamma \mathrm{s}}\right)$ increases with an increase in the depth factor $\left(D_{f} / B_{0}\right)$. Due to an increase in the depth factor $\left(D_{f} / B_{0}\right)$, surcharge weight increases, which increases the passive resistance and hence increases the seismic bearing capacity factor.

4.1.4. Effect on $N_{\gamma \mathrm{e}} / N_{\gamma \mathrm{s}}$ due to Variation of Seismic Accelerations $\left(k_{h}\right.$ and $\left.k_{v}\right)$. From Figures $6-9$, it is seen that the normalized reduction factor $\left(N_{\gamma \mathrm{e}} / N_{\gamma \mathrm{s}}\right)$ decreases along 


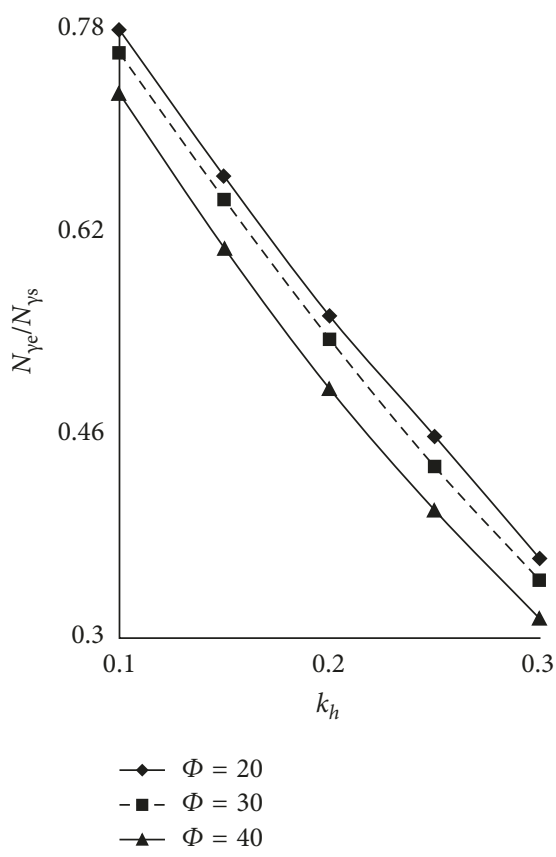

FIgURE 6: The variations of the bearing capacity coefficient with respect to seismic acceleration $\left(k_{h}\right)$ at different soil friction angles $\left(\Phi=20^{\circ}, 30^{\circ}\right.$, and $\left.40^{\circ}\right)$ for $2 c / B_{0}=0.25, D_{f} / B_{0}=0.5$, and $k_{v}=k_{h} / 2$.

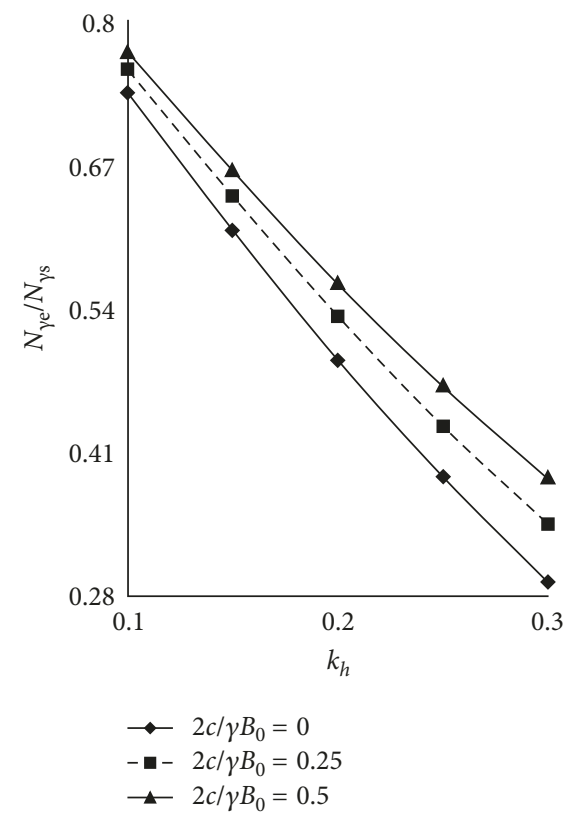

FIGURE 7: The variations of the bearing capacity coefficient with respect to seismic acceleration $\left(k_{h}\right)$ at different cohesion factors $\left(2 c / B_{0}=0,0.25\right.$, and 0.5$)$ for $\Phi=30^{\circ}, \delta=\Phi / 2, D_{f} / B_{0}=0.5$, and $k_{v}=k_{h} / 2$.

with an increase in horizontal seismic acceleration $\left(k_{h}\right)$. And Figure 9 shows the variations of the normalized reduction factor $\left(N_{\gamma \mathrm{e}} / N_{\gamma \mathrm{s}}\right)$ with respect to seismic acceleration $\left(k_{h}\right)$ at different vertical seismic accelerations $\left(k_{v}=0, k_{h} / 2\right.$, and $\left.k_{h}\right)$ for $\Phi=30^{\circ}, D_{f}=0.5$, and $2 c / \gamma B_{0}=0.25$. It is seen that the normalized reduction factor $\left(N_{\gamma \mathrm{e}} / N_{\gamma \mathrm{s}}\right)$ decreases with the increase

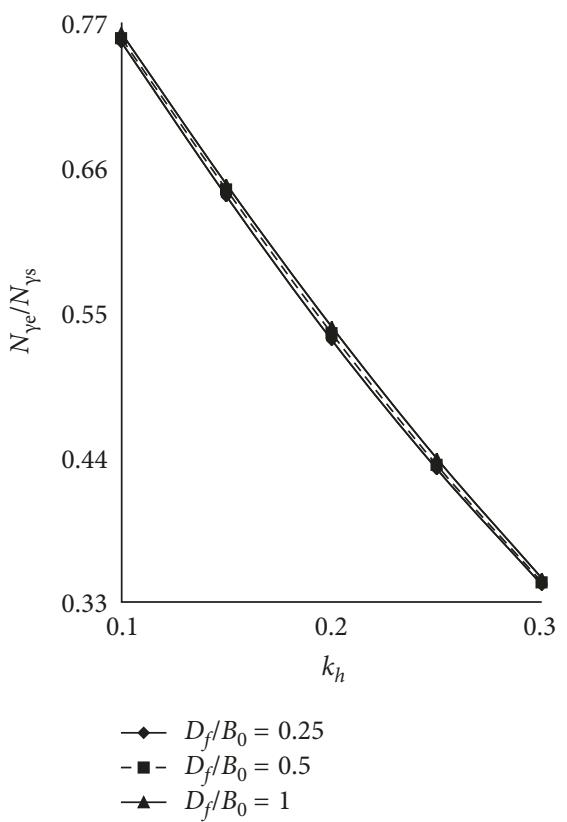

FIGURE 8: The variations of the bearing capacity coefficient with respect to seismic acceleration $\left(k_{h}\right)$ at different depth factors $\left(D_{f} / B_{0}=0.25,0.5\right.$, and 1$)$ for $\Phi=30^{\circ}, \delta=\Phi / 2,2 c / B_{0}=0.25$, and $k_{v}=k_{h} / 2$.

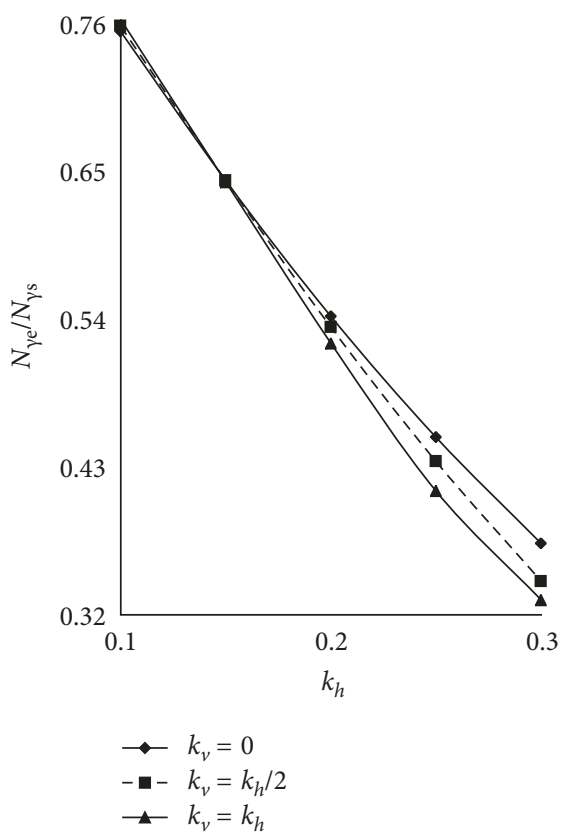

FIGURE 9: The variations of the bearing capacity coefficient with respect to seismic acceleration $\left(k_{h}\right)$ at different vertical seismic accelerations $\left(k_{v}=0, k_{h} / 2\right.$, and $\left.k_{h}\right)$ for $\Phi=30^{\circ}, 2 c / B_{0}=0.25, D_{f} / B_{0}=0.5$, and $\delta=\Phi / 2$.

in vertical seismic acceleration $\left(k_{v}\right)$ also. Due to an increase in seismic acceleration and due to the sudden movement of different waves, the disturbance in the soil particles increases, which allows more soil mass to participate in the vibration and hence decreases its resistance against bearing capacity. 
4.1.5. Comparison of Result. A detailed comparative study of the present analysis with previous research on similar type of works with different approaches is done here. Figure 10 and Table 3 show the comparison of a pseudodynamic bearing capacity coefficient obtained from the present analysis with previous seismic analyses with respect to different seismic accelerations $\left(k_{h}=0.1,0.2\right.$, and 0.3$)$ for $\Phi=30^{\circ}$. It is seen that, for the lower value of seismic accelerations here in Figure 10, $k_{h}=0.2$, the values obtained from the present study are less than the values obtained from Soubra [10] (M1 and M2) [17]. But when horizontal seismic acceleration increases from 0.2, the bearing capacity coefficient also increases gradually, and at $k_{h}=0.3$, the present analysis provides greater value in comparison to all the compared methods. At $k_{h}=0.1$, around $7.5 \%, 24 \%$, and $29 \%$ decrease in $N_{\gamma e}$ coefficient, and at $k_{h}=0.2$, around $2 \%, 15 \%$, and $12 \%$ decrease in $N_{\gamma \mathrm{e}}$ coefficient in comparison to that in Soubra [10] (M1 and M2) and Ghosh [17], respectively. But at $k_{h}=0.3$, it increases around $26 \%, 16 \%$, and $48 \%$, respectively, in comparison with the respective analyses.

The performance results, that is, pseudodynamic bearing capacity coefficients obtained by the HSOS algorithm are compared with other metaheuristic optimization algorithms. Table 4 shows the performance result obtained by DE [45], PSO [46], ABC [47], HS [48], BSA [49], ABSA [50], SOS [33], and HSOS [39] algorithms at different conditions that are compared here. From this table, it is observed that the performance result, that is, pseudodynamic bearing capacity coefficient $\left(N_{\gamma e}\right)$ obtained from this HSOS algorithm is lesser than the other compared algorithms in different soil and seismic conditions. From the above investigations, it can be said that HSOS algorithm can satisfactorily be used to evaluate the seismic bearing capacity of shallow strip footing suggested here.

\section{Numerical Analysis}

The numerical modeling of dynamic analysis of shallow strip footing is performed using a finite element software, PLAXIS 2D (v-8.6), which is equipped with features to deal with various aspects of complex structures and study the soil-structure interaction effect. In addition to static loads, the dynamic module of PLAXIS also provides a powerful tool for modeling the dynamic response of a soil structure during an earthquake.

5.1. Numerical Modeling. A two-dimensional geometrical model is prepared that is to be composed of points, lines, and other components in the $x-y$ plane. The PLAXIS mesh generator based on the input of the geometry model automatically performs the generation of a mesh at an element level. The shallow strip footing was modeled as a plane strain, and 15 nodded triangular elements are used to simulate the foundation soil. The extension of the mesh was taken $100 \mathrm{~m}$ wide and $30 \mathrm{~m}$ depth as the earthquake forces cannot affect the vertical boundaries. Standard earthquake boundaries are applied for earthquake loading conditions using SMC files, and then the mesh is generated. Cluster refinement of the

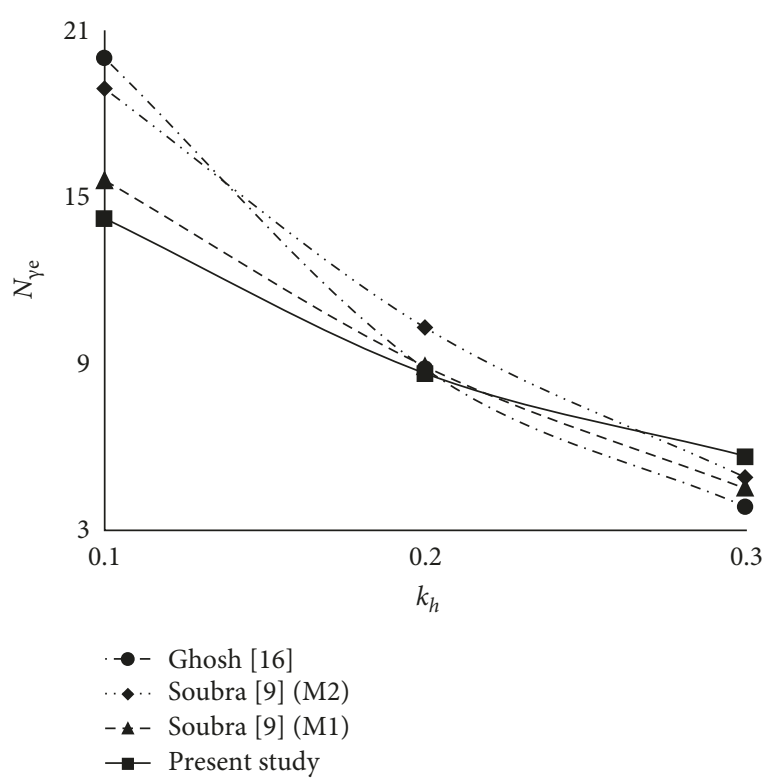

FIGURE 10: The comparison of pseudodynamic bearing capacity coefficient obtained from present analysis with previous seismic analyses with respect to different seismic accelerations $\left(k_{h}=0.1,0.2\right.$, and 0.3 ) for $\Phi=30^{\circ}$.

mesh is followed to obtain precise medium-sized mesh. HS small model was used to incorporate dynamic soil properties of the soil samples. Two different soil samples were used to analyze the shallow strip footing under seismic loading condition as shown in Table 5. A uniformly distributed load of $100 \mathrm{kN} / \mathrm{m}$ applying on the section of the foundation along with different surcharge loads to represent the load coming from superstructure is analyzed in this paper as shown in Figure 11. Initial stresses are generated after turning off the initial pore water pressure tool.

5.2. Calculation. During the calculation stage, three steps are adopted where, in the first step, calculations are done for plastic analysis where applied vertical load and weight of soil are activated. In the second step, calculations are made for dynamic analysis where earthquake data are incorporated as SMS file. And, in the final step, FOS is determined by the $c-\Phi$ reduction method. El Salvador 2001 earthquake data (moment magnitude, $M_{w}=7.6$ ) are given as input in the dynamic calculation as SMC file as shown in Figure 12. The vertical settlement of the foundation and the corresponding factor at safety of each condition obtained from the numerical modeling are obtained. Figures 13 and 14 show the deformed mesh and vertical displacement contour, respectively, after undergoing staged calculations.

5.3. Numerical Validation. Finite element model of shallow strip footing embedded in $c-\Phi$ soil is analyzed in PLAXIS$8.6 \mathrm{v}$ for the validation of the analytical solution. The results obtained from this analytical analysis are compared with the numerical solutions to validate the analysis. At first, 
TABLe 3: Comparison of seismic bearing capacity coefficient $\left(N_{\gamma \mathrm{e}}\right)$ for different values of $k_{h}$ and $k_{v}$ with $\Phi=30^{\circ}$.

\begin{tabular}{|c|c|c|c|c|c|c|c|c|c|c|}
\hline \multirow[t]{2}{*}{$k_{h}$} & \multicolumn{2}{|c|}{ Present study } & \multicolumn{2}{|c|}{ Ghosh [17] } & \multicolumn{2}{|c|}{$\begin{array}{l}\text { Budhu and Al-Karni } \\
\text { [7] }\end{array}$} & \multicolumn{2}{|c|}{$\begin{array}{l}\text { Choudhury and } \\
\text { Subba Rao [13] }\end{array}$} & \multicolumn{2}{|c|}{ Soubra [10] } \\
\hline & $k_{v}=k_{h} / 2$ & $k_{v}=k_{h}$ & $k_{v}=k_{h} / 2$ & $k_{v}=k_{h}$ & $k_{v}=k_{h} / 2$ & $k_{v}=k_{h}$ & $k_{v}=k_{h} / 2$ & $k_{v}=k_{h}$ & M1 & M2 \\
\hline 0.1 & 14.43 & 14.23 & 20.39 & 20.04 & 10.21 & 9.46 & 8.4 & 7.76 & 15.6 & 18.9 \\
\hline 0.2 & 8.78 & 8.65 & 9.98 & 8.82 & 3.81 & 2.86 & 2.85 & 2 & 8.9 & 10.3 \\
\hline 0.3 & 5.68 & 5.67 & 3.85 & 2.35 & 1.21 & 0.56 & 0.98 & 0.29 & 4.5 & 4.9 \\
\hline
\end{tabular}

TABle 4: Comparison of seismic bearing capacity coefficient $\left(N_{\gamma \mathrm{e}}\right)$ obtained by different standard algorithms.

\begin{tabular}{|c|c|c|c|c|c|c|c|c|c|}
\hline$\Phi$ & $k_{h}$ & $\mathrm{DE}$ & PSO & $\mathrm{ABC}$ & HS & BSA & ABSA & SOS & HSOS \\
\hline \multicolumn{10}{|c|}{ (a) $2 c / \gamma B_{0}=0.25, D_{f} / B_{0}=0.5$, and $k_{v}=k_{h} / 2$} \\
\hline \multirow{2}{*}{$20^{\circ}$} & 0.1 & 11.54 & 11.771 & 11.255 & 11.62 & 11.25 & 11.284 & 11.248 & 11.247 \\
\hline & 0.2 & 8.714 & 8.524 & 8.11 & 8.73 & 8.1 & 8.51 & 8.02 & 8.01 \\
\hline \multirow{2}{*}{$30^{\circ}$} & 0.1 & 34.681 & 34.854 & 34.535 & 34.942 & 34.53 & 34.591 & 34.53 & 34.529 \\
\hline & 0.2 & 24.514 & 24.641 & 24.319 & 24.43 & 24.319 & 24.361 & 24.32 & 24.314 \\
\hline \multirow{2}{*}{$40^{\circ}$} & 0.1 & 138.90 & 139.12 & 138.85 & 139.54 & 138.83 & 138.99 & 138.9 & 138.82 \\
\hline & 0.2 & 94.768 & 95.546 & 94.78 & 94.89 & 94.77 & 94.82 & 94.77 & 94.766 \\
\hline \multicolumn{10}{|c|}{ (b) $2 c / \gamma B_{0}=0.5, D_{f} / B_{0}=0.75$, and $k_{v}=k_{h} / 2$} \\
\hline \multirow{2}{*}{$20^{\circ}$} & 0.1 & 16.46 & 16.363 & 16.359 & 16.512 & 16.37 & 16.45 & 16.361 & 16.359 \\
\hline & 0.2 & 12.53 & 12.325 & 12.581 & 12.524 & 12.33 & 12.812 & 12.324 & 12.321 \\
\hline \multirow{2}{*}{$30^{\circ}$} & 0.1 & 46.91 & 46.579 & 46.942 & 46.76 & 46.59 & 46.751 & 46.575 & 46.573 \\
\hline & 0.2 & 33.931 & 33.823 & 34.15 & 33.99 & 33.83 & 33.97 & 33.816 & 33.811 \\
\hline \multirow{2}{*}{$40^{\circ}$} & 0.1 & 174.76 & 174.68 & 174.691 & 174.93 & 174.67 & 174.81 & 174.69 & 174.65 \\
\hline & 0.2 & 121.69 & 121.59 & 121.61 & 121.59 & 121.58 & 121.561 & 121.58 & 121.54 \\
\hline
\end{tabular}

TABLE 5: HS small model soil parameters for PLAXIS-8.6v.

\begin{tabular}{lccccccccccc}
\hline Sample & $\gamma(\mathrm{kPa})$ & $c(\mathrm{kPa})$ & $\Phi$ & $\psi$ & $\nu$ & $E_{50}^{\text {ref }}(\mathrm{kPa})$ & $E_{\text {oed }}^{\text {ref }}(\mathrm{kPa})$ & $E_{\text {ur }}^{\text {ref }}(\mathrm{kPa})$ & $m$ & $G_{0}(\mathrm{kPa})$ & $\gamma_{0.7}$ \\
\hline S1 & 20.9 & 0.5 & 32 & 2 & 0.2 & $1.00 E+4$ & $1.00 E+4$ & $3.00 E+4$ & 0.5 & $1.00 E+5$ & $1.00 E-4$ \\
S2 & 19.9 & 0.2 & 28 & 0 & 0.2 & $1.25 E+4$ & $1.00 E+4$ & $3.75 E+4$ & 0.5 & $1.30 E+5$ & $1.25 E-4$ \\
\hline
\end{tabular}

settlement of foundation is calculated analytically using two classical equations, such as

Richards et al.'s [12] seismic settlement equation:

$$
s_{e}=0.174 \frac{V^{2}}{A g}\left[\frac{k_{h}}{A}\right]^{-4} \tan \alpha_{\mathrm{AE}},
$$

where $V$ is the peak velocity for the design earthquake $(\mathrm{m} / \mathrm{sec}), A$ is the acceleration coefficient for the design earthquake, and $g$ is the acceleration due to gravity, and the value of $\alpha_{\mathrm{AE}}$ depends on $\Phi$ and critical acceleration $k_{h}^{*}$.

Terzaghi's [2] immediate settlement equation:

$$
s_{i}=q_{n} B_{0} \frac{\left(1-v^{2}\right)}{E} I_{f},
$$

where $q_{n}$ is the net foundation pressure, $q_{n}=\left\lfloor Q_{\text {ult }}-\gamma D_{f}\right\rfloor /$ FOS, $v$ is the Poisson ratio, $E$ is the Young modulus of soil, and $I_{f}$ is the influence factor for shallow strip footing. Here, $Q_{\text {ult }}$ is the pseudodynamic ultimate bearing capacity which is obtained from (39).

The dynamic soil properties taken in numerical modeling [Plaxis-8.6v] are used same in the analytical formulation to validate it. Results obtained from the analytical solution and numerical modeling have been tabulated in Table 6 . Two different types of soil models have been analyzed. Settlement of shallow foundation for the corresponding soil model is calculated using (41) and (42). Settlement values obtained from the finite element model in PLAXIS are also tabulated. It is seen that settlement obtained from analytical solution is slightly in lower side in comparison with the settlement obtained from PLAXIS-8.6v as in the analytical settlement calculation, the only initial settlement is considered. So, the formulation of pseudodynamic bearing capacity is well justified after the numerical validation.

\section{Conclusion}

Using the pseudodynamic approach, the effect of the shear wave and primary wave velocities traveling through the soil layer and the time and phase difference along with the horizontal and vertical seismic accelerations are used to evaluate the seismic bearing capacity of the shallow strip footing. A mathematical formulation is suggested for simultaneous resistance of unit weight, surcharge and cohesion 


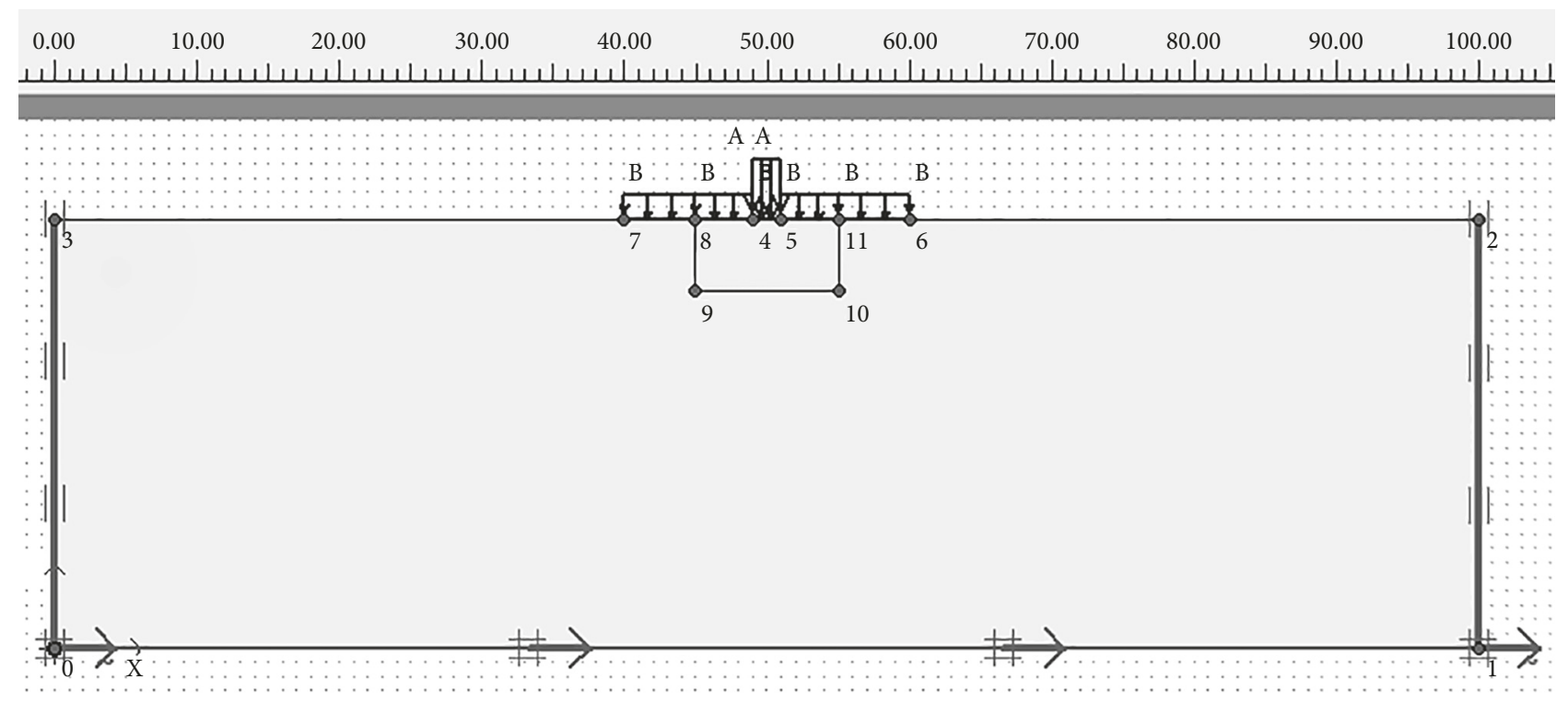

FIgURE 11: Finite element geometry and foundation load along with surcharge load.

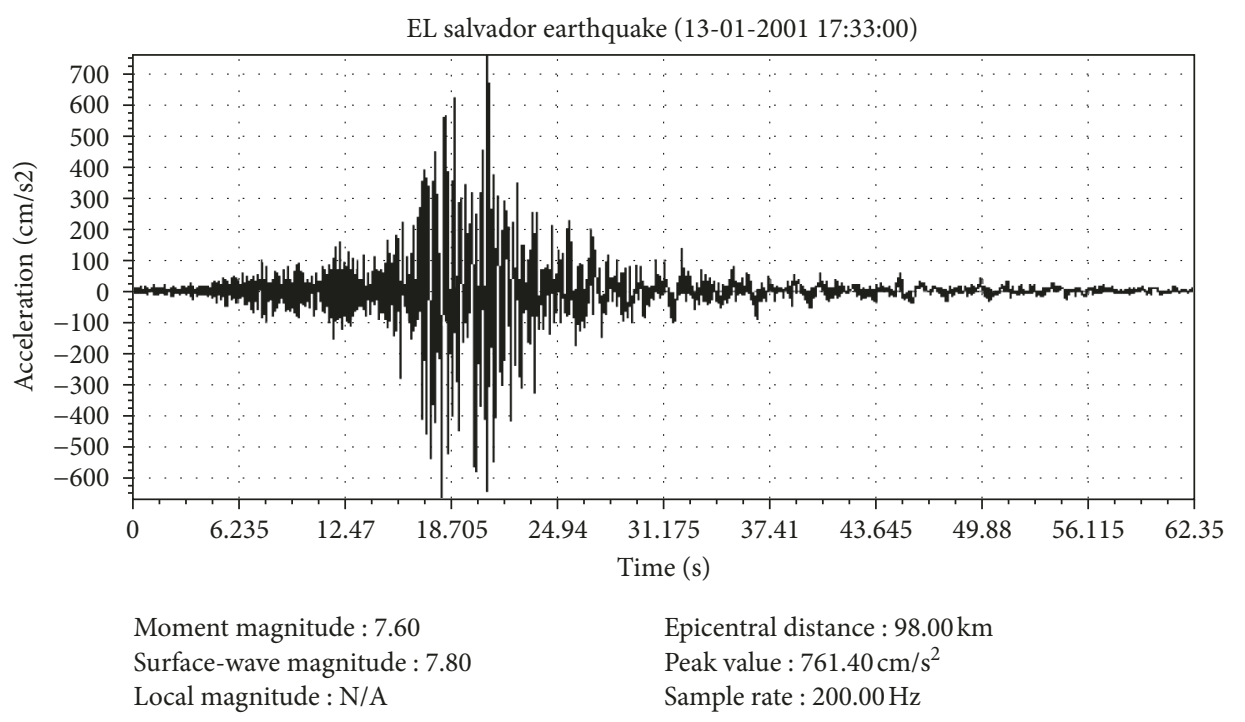

FIGURe 12: El Salvador 2001 earthquake data.

using upper-bound limit analysis method. A composite failure mechanism which includes both planer and log-spiral zone is considered here to develop this mathematical model for the shallow strip footing resting on $c-\Phi$ soil. The HSOS algorithm is used to solve this problem. The advantage of this HSOS algorithm is that it can improve the searching capability of the algorithm for attaining the global optimum. From the comparison, the results obtained by the HSOS algorithm with other standard algorithms show the acceptability of the results in all soil and seismic conditions. Hence, using the HSOS algorithm, the coefficient of seismic bearing capacity is presented in a tabular form. Numerical modeling of shallow strip footing is also analyzed using PLAXIS-8.6v software for the validation of the analytical solution. It is observed that the results obtained from this analytical analysis are well justified with the numerical solutions. The effect of various parameters such as soil friction angle $(\Phi)$, seismic accelerations $\left(k_{h}\right.$ and $\left.k_{v}\right)$, cohesion factor $\left(2 c / \gamma B_{0}\right)$, and depth factor $\left(D_{f} / B_{0}\right)$ is studied here. It is seen that the pseudodynamic bearing capacity coefficient $\left(N_{\gamma \mathrm{e}}\right)$ increases with the increase in $\Phi, 2 c / \gamma B_{0}$, and $D_{f} / B_{0}$, but it decreases with the increase in horizontal and vertical seismic accelerations $\left(k_{h}\right.$ and $\left.k_{v}\right)$. The values obtained from the present analysis are thoroughly compared with the available pseudostatic analysis as well as pseudodynamic analysis values, and it is seen that the values obtained from the present study are comparable reasonably. Using the values as provided in Tables 1 and 2, the ultimate bearing capacity of foundation under seismic loading condition can be evaluated. 


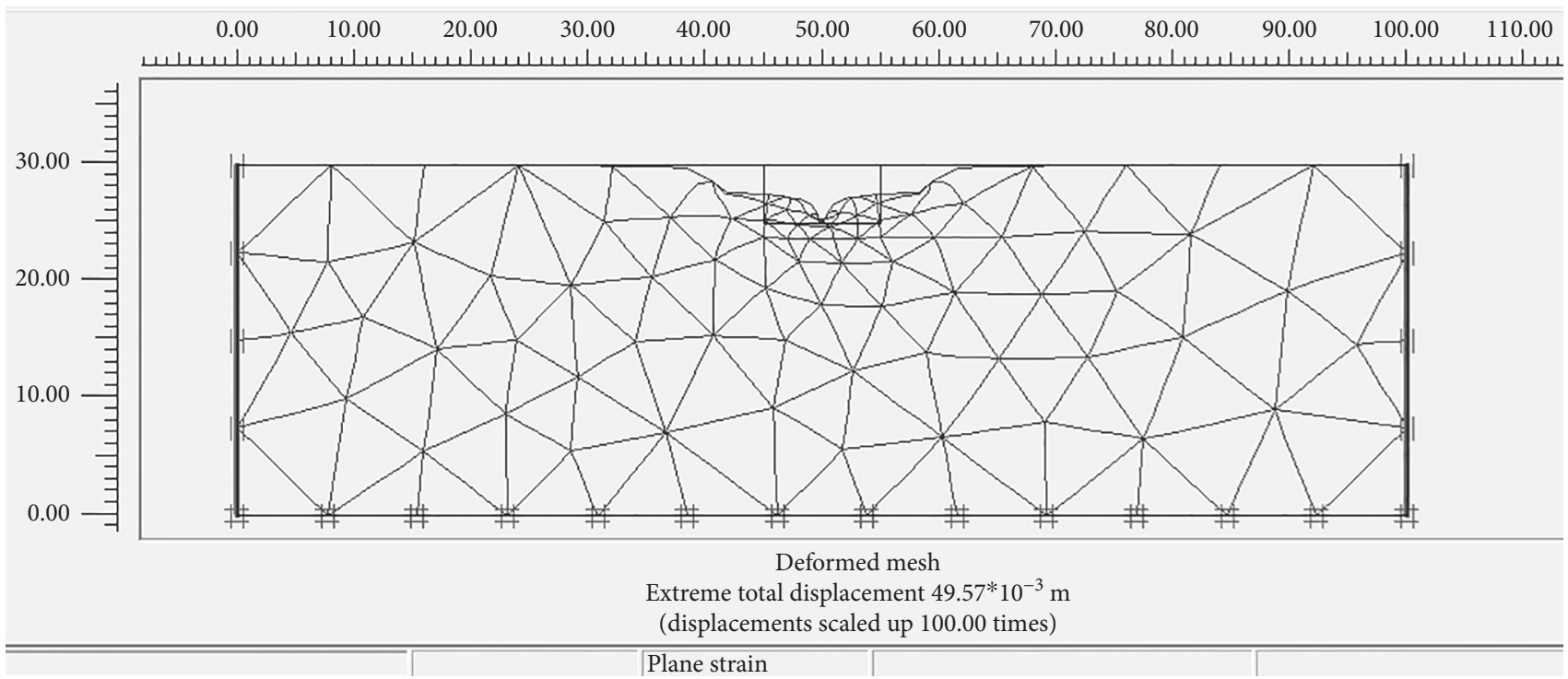

FIgURE 13: The deformed mesh of model after calculation.

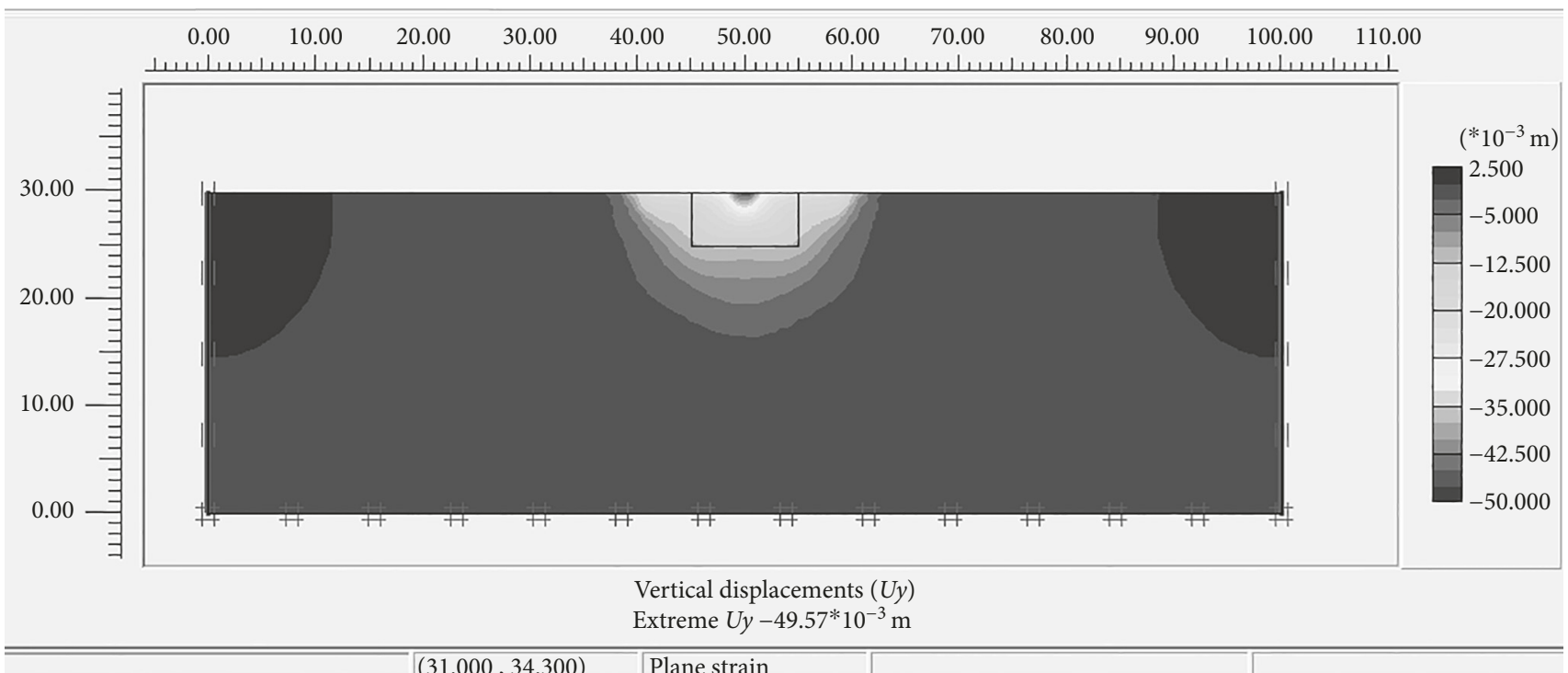

FIgURe 14: Vertical displacement contour after calculation.

TABLe 6: Comparison of settlements obtained from numerical and analytical analyses.

\begin{tabular}{|c|c|c|c|c|c|c|c|}
\hline \multirow{3}{*}{ Soil samples } & \multirow{3}{*}{ Depth factor $\left(D_{f} / B_{0}\right)$} & \multirow{2}{*}{\multicolumn{2}{|c|}{$\begin{array}{c}\text { Numerical solution } \\
\text { PLAXIS-8.6v }\end{array}$}} & \multicolumn{4}{|c|}{ Analytical solution } \\
\hline & & & & \multicolumn{2}{|c|}{ Richards et al. [12] } & \multirow{2}{*}{$\begin{array}{c}\text { Present analysis } \\
N_{\gamma \mathrm{e}}\end{array}$} & \multirow{2}{*}{$\begin{array}{c}\text { Terzaghi }[2] \\
\text { Settlement }(\mathrm{mm})\end{array}$} \\
\hline & & FOS & Settlement $(\mathrm{mm})$ & $k_{h}^{*}$ & Settlement $(\mathrm{mm})$ & & \\
\hline \multirow{4}{*}{ Sample 1} & 0 & 1.12 & 49.57 & 0.02 & 127 & 41 & 48.97 \\
\hline & 0.25 & 1.95 & 42.82 & 0.14 & 18.27 & 53 & 36.01 \\
\hline & 0.5 & 2.71 & 41.47 & 0.24 & 10.65 & 68 & 33.07 \\
\hline & 1 & 3.19 & 40.1 & 0.28 & 9.13 & 75 & 30.61 \\
\hline \multirow{4}{*}{ Sample 2} & 0 & 1.03 & 47.45 & 0.01 & 255 & 37 & 36.6 \\
\hline & 0.25 & 1.59 & 40.99 & 0.1 & 25.58 & 49 & 31.08 \\
\hline & 0.5 & 2.14 & 38.22 & 0.18 & 18.27 & 64 & 30.0 \\
\hline & 1 & 2.61 & 34.47 & 0.25 & 10.23 & 72 & 27.33 \\
\hline
\end{tabular}




\section{Nomenclature}

\begin{tabular}{|c|c|}
\hline $2 c / \gamma B_{0}$ & Cohesion factor \\
\hline$B_{0}:$ & Width of the footing \\
\hline$C:$ & Cohesion of soil \\
\hline$D_{f}:$ & Depth of footing below ground surface \\
\hline$D_{f} / B_{0}:$ & Depth factor \\
\hline$g:$ & Acceleration due to gravity \\
\hline G: & Shear modulus of soil \\
\hline$k_{h}, k_{v}:$ & Horizontal and vertical seismic accelerations \\
\hline$N_{c}, N_{q}, N_{\gamma}:$ & Bearing capacity coefficients \\
\hline$N_{\gamma \mathrm{e}}:$ & $\begin{array}{l}\text { Optimized single seismic bearing capacity } \\
\text { coefficient }\end{array}$ \\
\hline$N_{\gamma s}:$ & $\begin{array}{l}\text { Optimized single static bearing capacity } \\
\text { coefficient }\end{array}$ \\
\hline$N_{\gamma \mathrm{e}} / N_{\gamma \mathrm{s}}:$ & Normalized reduction factor \\
\hline PL: & Uniformly distributed column load \\
\hline q: & Surcharge loadings \\
\hline $0, r$ & $\begin{array}{l}\text { Initial and final radii of the log-spiral zone } \\
\text { (i.e., } \mathrm{BE} \text { and } \mathrm{BD}) \text {, respectively }\end{array}$ \\
\hline t: & Time of vibration \\
\hline$T:$ & Period of lateral shaking \\
\hline$V_{1}, V_{2}$, and $V_{\theta}$ : & $\begin{array}{l}\text { Absolute and relative velocities, } \\
\text { respectively }\end{array}$ \\
\hline$V_{p}:$ & Primary wave velocity \\
\hline$V_{s}:$ & Shear wave velocity \\
\hline$\alpha_{1}, \alpha_{2}:$ & $\begin{array}{l}\text { Base angles of triangular elastic zone under } \\
\text { the foundation }\end{array}$ \\
\hline$\beta:$ & $\begin{array}{l}\text { Angle that makes the log-spiral part in log- } \\
\text { spiral mechanism }\end{array}$ \\
\hline$\gamma:$ & Unit weight of soil medium \\
\hline$\lambda, \eta:$ & Lame's constant \\
\hline$v:$ & Poisson's ratio of the soil medium \\
\hline$\Phi:$ & Angle of internal friction of the soil \\
\hline$\omega:$ & Angular frequency \\
\hline SOS: & Symbiosis organisms search \\
\hline & Simple quadratic interpolation \\
\hline OS: & Hybrid symbiosis organisms search. \\
\hline
\end{tabular}

\section{Conflicts of Interest}

The authors declare that there are no conflicts of interest regarding the publication of this paper.

\section{References}

[1] L. Prandtl, "Uber die Eindringungstestigkeit Plastisher Baustoffe und Die Festigkeit von Schneiden," Zeitschrift Für Angewandte Mathematik und Mechanik, vol. 1, no. 1, pp. 15-30, 1921, (in German).

[2] K. Terzaghi, Theoretical Soil Mechanics, John Wiley \& Sons, NewYork, NY, USA, 1943.

[3] G. G. Meyerhof, "The ultimate bearing capacity of foundations on slopes," in Proceedings of the 4th International Conference on Soil Mechanics and Foundation Engineering, pp. 384-386, London, UK, August 1957.

[4] G. G. Meyerhof, "Some recent research on the bearing capacity of foundations," Canadian Geotechnical Journal, vol. 1, no. 1, pp. $16-26,1963$
[5] A. S. Vesic, "Analysis of ultimate loads of shallow foundations," Journal of the Soil Mechanics and Foundations Division, vol. 99, no. 1, pp. 45-43, 1973.

[6] S. Saran and R. K. Agarwal, "Bearing capacity of eccentrically obliquely loaded footing," Journal of Geotechnical Engineering, vol. 117, no. 11, pp. 1669-1690, 1991.

[7] M. Budhu and A. Al-Karni, "Seismic bearing capacity of soils," Geotechnique, vol. 43, no. 1, pp. 181-187, 1993.

[8] L. Dormieux and A. Pecker, "Seismic bearing capacity of foundation on cohesionless soil," Journal of Geotechnical Engineering, vol. 121, no. 3, pp. 300-303, 1995.

[9] A. H. Soubra, "Discussion of "seismic bearing capacity and settlements of foundations", Journal of Geotechnical Engineering, vol. 120, no. 9, pp. 1634-1636, 1994.

[10] A. H. Soubra, "Seismic bearing capacity of shallow strip footings in seismic conditions," Proceedings of the Institution of Civil Engineers-Geotechnical Engineering, vol. 125, no. 4, pp. 230-241, 1997.

[11] A. H. Soubra, "Upper bound solutions for bearing capacity of foundations," Journal of Geotechnical and Geoenvironmental Engineering, vol. 125, no. 1, pp. 59-69, 1999.

[12] R. Richards, D. G. Elms, and M. Budhu, "Seismic bearing capacity and settlements of foundations," Journal of Geotechnical Engineering, vol. 119, no. 4, pp. 662-674, 1993.

[13] D. Choudhury and K. S. Subba Rao, "Seismic bearing capacity of shallow strip footings," Geotechnical and Geological Engineering, vol. 23, no. 4, pp. 403-418, 2005.

[14] J. Kumar and P. Ghosh, "Seismic bearing capacity for embedded footing on sloping ground," Geotechnique, vol. 56, no. 2, pp. 133-140, 2006.

[15] A. H. Shafiee and M. Jahanandish, "Seismic bearing capacity factors for strip footings," in Proceedings of the National Congress on Civil Engineering, Ferdowsi University of Mashhad, Mashhad, Iran, 2010.

[16] D. Chakraborty and J. Kumar, "Seismic bearing capacity of shallow embedded foundations on a sloping ground surface," International Journal of Geomechanics, vol. 15, no. 1, p. 04014035, 2014.

[17] P. Ghosh, "Upper bound solutions of bearing capacity of strip footing by pseudo-dynamic approach," Acta Geotechnica, vol. 3, pp. 115-123, 2008.

[18] A. Saha and S. Ghosh, "Pseudo-dynamic analysis for bearing capacity of foundation resting on $c-\Phi$ soil," International Journal of Geotechnical Engineering, vol. 9, no. 4, pp. 379-387, 2014.

[19] A. Sengupta and A. Upadhyay, "Locating the critical failure surface in a slope stability analysis by genetic algorithm," Applied Soft Computing, vol. 9, no. 1, pp. 387-392, 2009.

[20] Y. M. Cheng, L. Chi, S. Li, and W. B. Wei, "Particle swarm optimization algorithm for location of critical non-circular failure surface in two-dimensional slope stability analysis," Computer and Geotechnics, vol. 34, no. 2, pp. 92-103, 2007.

[21] S. K. Das, "Slope stability analysis using genetic algorithm," Electronic Journal of Geotechnical Engineering, vol. 10A, 2005.

[22] K. Deb and M. Goyal, "Optimizing engineering designs using combined genetic search," in Proceedings of Seventh International Conference on Genetic Algorithms, pp. 512-528, Michigan State University, East Lansing, MI, 1997.

[23] A. H. Gandomi, A. R. Kashani, M. Mousavi, and M. Jalalvandi, "Slope stability analyzing using recent swarm intelligence techniques," International Journal for Numerical and Analytical Methods in Geomechanics, vol. 39, no. 3, pp. 295-309, 2015. 
[24] A. T. C. Goh, "Genetic algorithm search for critical slip surface in multiple-wedge stability analysis," Canadian Geotechnical Journal, vol. 36, pp. 382-391, 1999.

[25] K. S. Kahatadeniya, P. Nanakorn, and K. M. Neaupane, "Determination of the critical failure surface for slope stability analysis using ant colony optimization," Engineering Geology, vol. 108, no. 1-2, pp. 133-141, 2009.

[26] Y.-C. Li, Y.-M. Chen, T. L. T. Zhan, D.-S. Ling, and P. J. Cleall, "An efficient approach for locating the critical slip surface in slope stability analysis using a real-coded genetic algorithm," Canadian Geotechnical Journal, vol. 47, no. 7, pp. 806-820, 2010.

[27] P. McCombie and P. Wilkinson, "The use of the simple genetic algorithm in finding the critical factor of safety in slope stability analysis," Computers and Geotechnics, vol. 29, no. 8, pp. 699-714, 2002.

[28] A. R. Zolfaghari, A. C. Heath, and P. F. McCombie, "Simple genetic algorithm search for critical non-circular failure surface in slope stability analysis," Computer and Geotechnics, vol. 32, no. 3, pp. 139-152, 2005.

[29] M. Ghazavi and S. Bazzazian Bonab, Optimization of reinforced concrete retaining walls using ant colony method, in Proceedings of the 3rd International Symposium on Geotechnical Safety and Risk (ISGSR 2011), N. Vogt, B. Schuppener, D. Straub, and G. Bräu, Eds., Bundesanstalt für Wasserbau, Munich, Germany, June 2011.

[30] S. Nama, A. K. Saha, and S. Ghosh, "Parameters optimization of geotechnical problem using different optimization algorithm," Geotechnical and Geological Engineering, vol. 33, no. 5, pp. 1235-1253, 2015.

[31] S. Nama, A. K. Saha, and S. Ghosh, "Improved backtracking search algorithm for pseudo dynamic active earth pressure on retaining wall supporting c- $\Phi$ backfill," Applied Soft Computing Journal, vol. 52, pp. 885-897, 2017.

[32] L. Li and F. Liu, Group Search Optimization for Applications in Structural Design, Springer-Verlag, Berlin, Heidelberg, Germany, 2011.

[33] M.-Y. Cheng and D. Prayogo, "Symbiotic organisms search: a new metaheuristic optimization algorithm," Computers \& Structures, vol. 139, pp. 98-112, 2014.

[34] S. Nama, A. K. Saha, and S. Ghosh, "Improved symbiotic organisms search algorithm for solving unconstrained function optimization," Decision Science Letters, vol. 5, no. 2016, pp. 361-380, 2016.

[35] M. Abdullahi, M. A. Ngadi, and S. M. Abdulhamid, "Symbiotic organism search optimization based task scheduling in cloud computing environment," Future Generation Computer Systems, vol. 56, pp. 640-650, 2016.

[36] G. G. Tejani, V. J. Savsanin, and V. K. Patel, “Adaptive symbiotic organisms search (SOS) algorithm for structural design optimization," Journal of Computational Design and Engineering, vol. 3, no. 3, pp. 226-249, 2016.

[37] M. Y. Cheng, D. Prayogo, and D. H. Tran, "Optimizing multiple-resources leveling in multiple projects using discrete symbiotic organisms search," Journal of Computing in Civil Engineering, vol. 30, no. 3, 2016.

[38] D. Prasad and V. Mukherjee, "A novel symbiotic organisms search algorithm for optimal power flow of power system with FACTS devices," Engineering Science and Technology, An International Journal, vol. 19, no. 1, pp. 79-89, 2016.

[39] S. Nama, A. K. Saha, and S. Ghosh, "A hybrid symbiosis organisms search algorithm and its application to real world problems," Memetic Computing, vol. 9, no. 3, pp. 261-280, 2017.
[40] K. Deep and K. N. Das, "Quadratic approximation based hybrid genetic algorithm for function optimization," Applied Mathematics and Computation, vol. 203, no. 1, pp. 86-98, 2008.

[41] A. Saha and S. Ghosh, "Pseudo-dynamic bearing capacity of shallow strip footing resting on $c-\Phi$ soil considering composite failure surface: bearing capacity analysis using pseudodynamic method," International Journal of Geotechnical Earthquake Engineering, vol. 6, no. 2, pp. 12-34, 2015.

[42] W. F. Chen and X. L. Liu, Limit Analysis in Soil Mechanics, Elsevier Science Publications Company, New York, NY, USA, 1990.

[43] M. Crepinšek, S. H. Liu, and M. Mernik, "Exploration and exploitation in evolutionary algorithms: a survey," $A C M$ Computing Surveys, vol. 45, no. 3, p. 33, 2013.

[44] W. Gong, Z. Cai, and C. X. Ling, "DE/BBO: a hybrid differential evolution with biogeography-based optimization for global numerical optimization," Soft Computing, vol. 15, pp. 645-665, 2011.

[45] R. Storn and K. Price, "Differential evolution-a simple and efficient heuristic for global optimization over continuous spaces," Journal of Global Optimization, vol. 11, no. 4, pp. 341-359, 1997.

[46] Y. Shi and R. Eberhart, "A modified particle swarm optimizer," in Proceedings of the IEEE World Congress on Computational Intelligence Evolutionary Computation, Anchorage, AK, USA, 1998.

[47] D. Karaboga and B. Basturk, "A powerful and efficient algorithm for numerical function optimization: artificial bee colony (ABC) algorithm," Journal of Global Optimization, vol. 39, no. 3, pp. 459-471, 2007.

[48] M. Mahdavi, M. Fesanghary, and E. Damangir, "An improved harmony search algorithm for solving optimization problems," Applied Mathematics and Computation, vol. 188, no. 2, pp. 1567-1579, 2007.

[49] P. Civicioglu, "Backtracking search optimization algorithm for numerical optimization problems," Applied Mathematics and Computation, vol. 219, no. 15, pp. 8121-8144, 2013.

[50] H. Duan and Q. Luo, "Adaptive backtracking search algorithm for induction magnetometer optimization," IEEE Transactions on Magnetics, vol. 50, no. 12, pp. 1-6, 2014. 


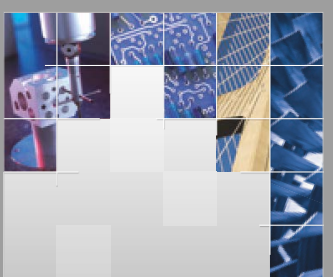

\section{Enfincering}
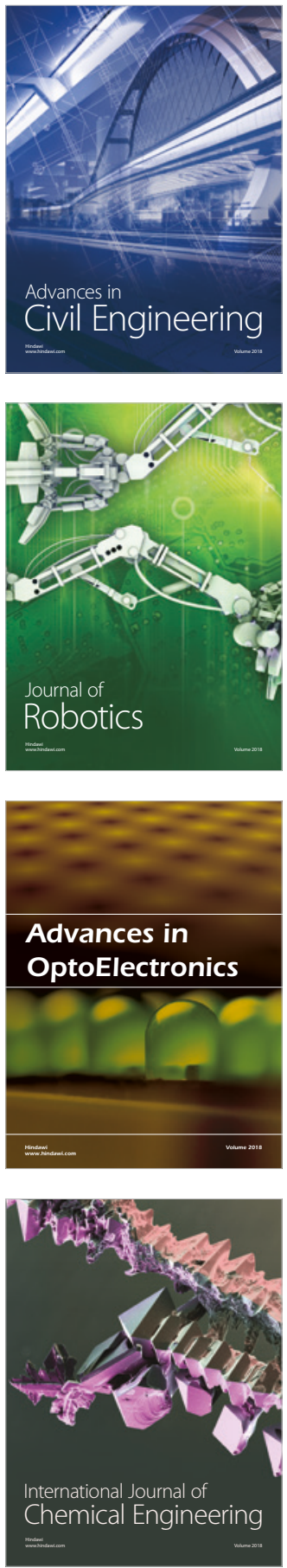

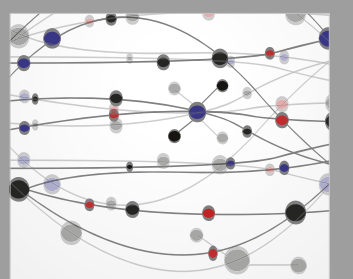

\section{Rotating \\ Machinery}

The Scientific World Journal

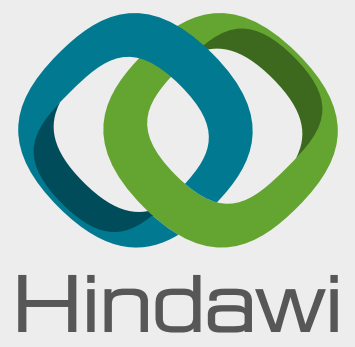

Submit your manuscripts at

www.hindawi.com
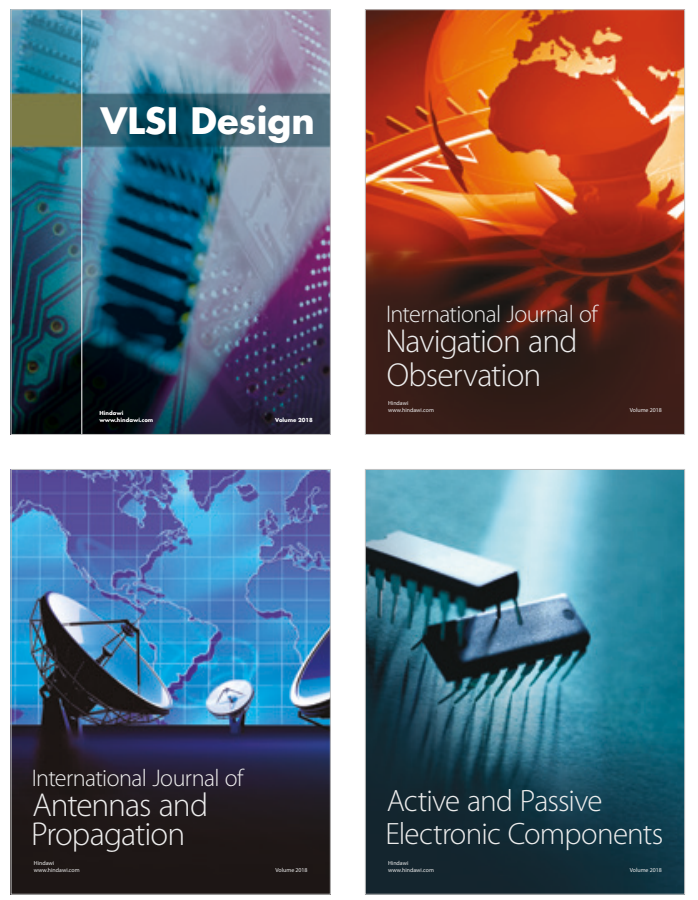
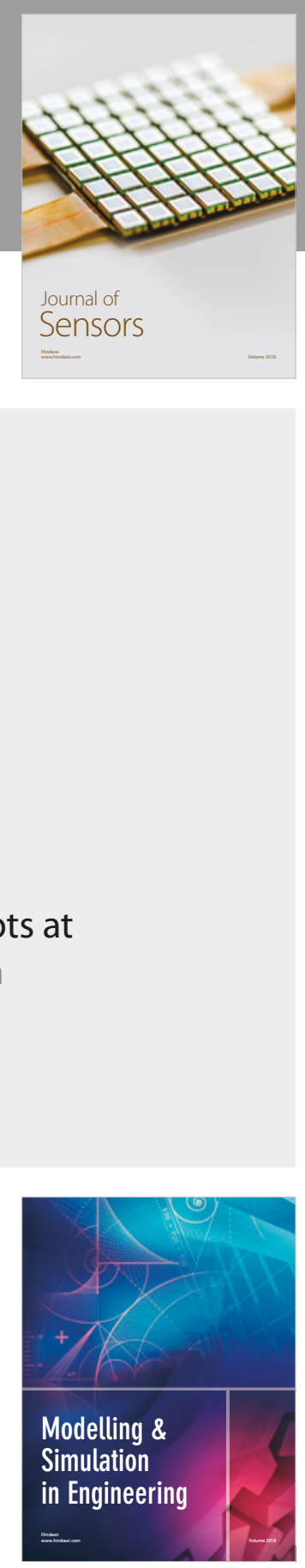

\section{Advances \\ Multimedia}
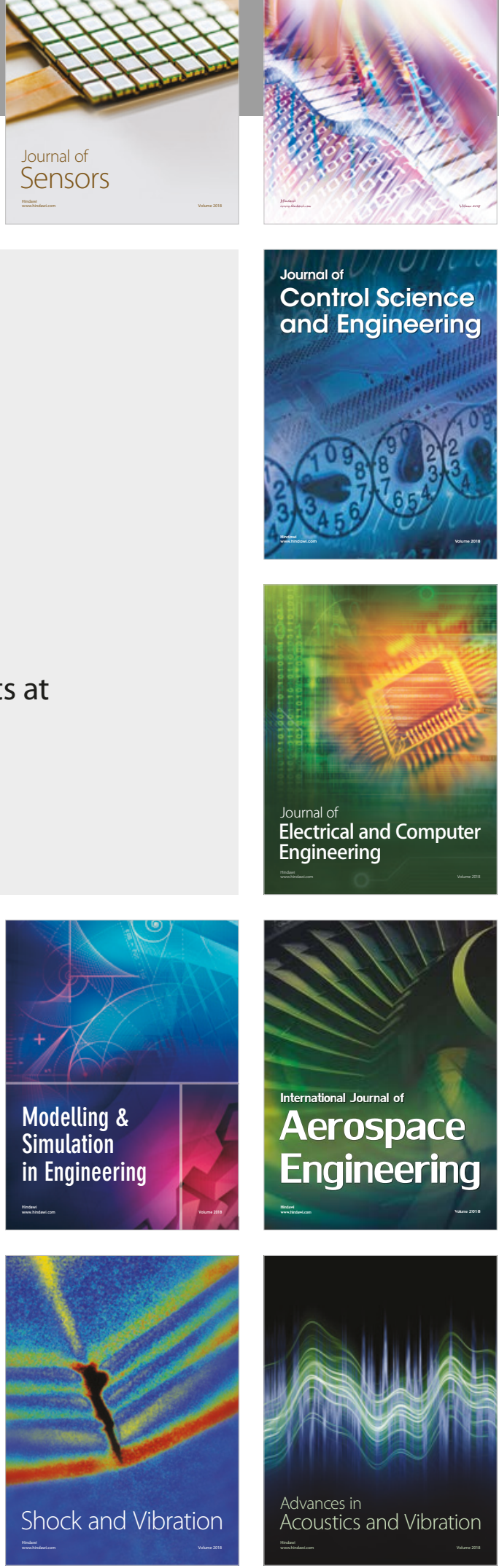